\title{
Reactivity of Polar Organometallic Compounds in Unconventional Reaction Media: Challenges and Opportunities
}

\author{
Joaquin García-Álvarez, ${ }^{*[a]}$ Eva Hevia, ${ }^{*[b]}$ and Vito Capriati*[c]
}

This paper is gratefully dedicated to the memory of Dr. Guy Lavigne

\begin{abstract}
Developing new green solvents in designing chemical products and processes or successfully employing the already existing ones is one of the key subjects in Green Chemistry and is especially important in Organometallic Chemistry, which is an interdisciplinary field. Can we advantageously use unconventional reaction media in place of current harsh organic solvents also for polar organometallic compounds? This Microreview critically analyses the state-of-the-art on this topic and showcases recent developments and breakthroughs which are becoming new research directions in this field. Because metals cover a vast swath of the periodic table, the content is organised into three Sections discussing the reactivity of organometallic compounds of s-, p- and $d$-block elements in unconventional solvents. The richness of bibliography reported witnesses the genuine, burning thirst for a deeper knowledge of this field, and forecasts an ever-bright future for Organometallics in Green Chemistry.
\end{abstract}

\section{Introduction}

"There are times when one can sense a sea change, a shift in the order of things that is profound and fundamental". ${ }^{[1]}$ A silent, but contagious revolution is taking place in the way of thinking and practising Organometallic Chemistry (OC) by academic and industrial groups worldwide, which is mainly driven by new insights, needs, and evidence on the horizon. OC plays an essential role across a wide spectrum of science, technology, medicine and industry, with a heavy impact on the environment, and still remains a core subject within the "grand challenges" or "big themes" (e.g., energy, materials, medicine) towards which priorities and policy often focus.

International strategies launched by institutions and organizations, such as The American Chemical Society's (ACS) Green Chemistry Institute Pharmaceutical Roundtable (GCIPR), strive for the need to replace conventional hazardous volatile organic compounds (VOCs) in favour of safe, green and biorenewable reaction media that are not based on crude petroleum. ${ }^{[2]}$ One large area of consumption of petroleum-based

[a] Dr. Joaquín García-Álvarez

Laboratorio de Compuestos Organometálicos y Catálisis

Departamento de Química Orgánica e Inorganica (IUQOEM)

Instituto Universitario de Química Organometálica "Enrique Moles"

Facultad de Química, Universidad de Oviedo

E-33071, Oviedo, Spain

E-mail: garciajoaquin@uniovi.es

[b] Prof. Eva Hevia

WestCHEM, Department of Pure and Applied Chemistry

University of Strathclyde, Glasgow, G1 1XL (UK)

Email: eva.hevia@strath.ac.uk

[c] Prof. Vito Capriati

Dipartimento di Farmacia-Scienze del Farmaco

Università di Bari "Aldo Moro", Consorzio C.I.N.M.P.I.S.

Via E. Orabona, 4 - I-70125 Bari, Italy

Email: vito.capriati@uniba.it chemicals in chemical transformations is, indeed, solvents used as reaction media, which account for $80-90 \%$ of mass utilization in a typical pharmaceutical/fine chemical operational process. Thus, the solvent itself is often a critical parameter especially in drug product manufacturing and is as well responsible for most waste generated in the chemical industries and laboratories. ${ }^{[3]}$

Following these considerations, some of the most critical and intriguing questions that arise are: Can we get traditional organic solvents out of organometallic reactions? ${ }^{[4]}$ Can we use protic, recyclable, biodegradable, and cheap unconventional solvents also for highly reactive organometallic compounds? Answering these questions would not only mean to break new ground towards sustainable solutions to the aforementioned challenges, but it could also be rewarding from an intellectual point of view in order to investigate to what extent a certain organometallic compound does not react with the intended unconventional solvent and, if that is the case, to explain why this occurs.

In this Microreview, recent selected contributions published in the literature tackling the above timely topics have been highlighted, but seminal references have also been critically analysed. The contents are organized into three main sections with subheadings according to the nature of the Metal-Carbon (M-C) bond. The impact played by unconventional solvents (e.g., water, deep eutectic solvents, ionic liquids, and supercritical $\mathrm{CO}_{2}$ ) on the chemistry of compounds of s-, p- and d-block elements has been discussed. Topics that have recently been reviewed are not further detailed here.

\section{Organometallic compounds of s-block elements}

Within the periodic table, the s-block elements are the 14 elements contained in the first two columns (Groups 1A and 2A) plus helium. They are unified by the fact that their valence electrons are in an s orbital, and are very reactive due to highly polar $\mathrm{M}-\mathrm{C}$ bonds. In this section, we will deal with the reactivity of organolithium and Grignard (organomagnesium) reagents in unconventional solvents.

\subsection{Reactivity in protic reaction media (water and deep eutectic solvents)}

Organolithium and Grignard reagents are among the most useful and versatile organometallic compounds in chemical synthesis, and functionalised organometallic species are very useful intermediates for the synthesis of many organic nonnatural and natural products. ${ }^{[5]}$ Opening chapters in classic organic textbooks, however, emphasise the need of the strict control of anhydrous conditions and the use of water-free reaction media for the successful handling of organometallic 
compounds with highly polarised $\mathrm{M}-\mathrm{C}$ bonds. Thus, at first sight, it might sound ridiculous to think to a protic solvent (e.g. water) as a potential "additive" (or, even worse, as a full component) for reaction media for carrying out s-block-metal-mediated organic transformations as these organometallics are extremely sensitive to traces of air and moisture. ${ }^{[6]}$ Nevertheless, a perusal of the modern and present-day literature reveals, from time to time, some "perplexing" reactions strangely "accelerated" by water. These deserve consideration and still need an explanation.

One of the first examples reported is the following. In order to label aromatics via hydrolysis of organometallics intermediates with tritiated water $\left(\mathrm{T}_{2} \mathrm{O}\right)$, Taylor made the observation that the most convenient way for the preparation of tritiated arenes was the addition of $n$-BuLi to a mixture of a bromoarene and wetted $\left(\mathrm{T}_{2} \mathrm{O}\right)$ sodium-dried $\mathrm{Et}_{2} \mathrm{O}$. This result is consistent with a lithium-bromine exchange reaction surprisingly occurring "at least as fast and most probably faster" than the expected reaction of $n$-BuLi with $\mathrm{T}_{2} \mathrm{O}$ (Scheme 1). ${ }^{[7]}$ The relative rates of deprotonation and of halogen-lithium exchange by organolithium compounds, however, have been a matter of controversy in the following years. ${ }^{[8]}$

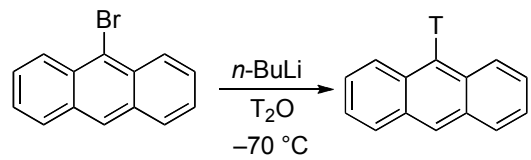

Scheme 1. Preparation of 9-tritium-labelled antracene.

Lithium carboxylates $\mathbf{1}$ are known to react with organolithium compounds 2 in $\mathrm{Et}_{2} \mathrm{O}$ to give high yields of the corresponding ketones 3 after considerable time of reflux (at least $24 \mathrm{~h}$ ). Under these conditions, tertiary alcohols $\mathbf{5}$ are not usually formed. However, if the reflux time is shorter (e.g. $30 \mathrm{~min}$ ), mixtures of ketones $\mathbf{3}$ and tertiary alcohols $\mathbf{5}$ are alternatively produced upon quenching with $\mathrm{H}_{2} \mathrm{O}$. This result implies that the excess organolithium 2 reacts during the hydrolysis with part of the ketone, which is formed by the hydrolysis of the intermediate adduct 4, faster than it reacts with water (Scheme 2). ${ }^{[9]}$ In highlighting these results, ${ }^{[10]}$ Keith Smith finally commented: "Shall we await the day when reactions of organolithiums are routinely performed in aqueous solution?"

In general, Lewis basic solvents increase the reactivity of organolithiums as they become an integral part of the organolithium aggregate and, once used as additives or ligands, they sometimes proved to be effective in contributing to the optimization of organolithium reactions. ${ }^{[11]}$

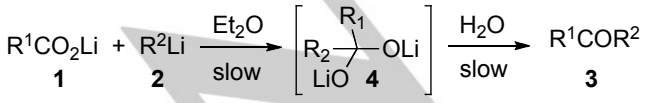

$$
\begin{aligned}
& \underset{\text { fast }}{\stackrel{\mathrm{R}^{2} \mathrm{Li}}{\longrightarrow}}\left[\mathrm{R}_{2} \underset{\mathrm{R}_{2}}{\stackrel{\mathrm{R}_{1}}{\digamma}} \mathrm{OLi}\right] \stackrel{\mathrm{H}_{2} \mathrm{O}}{\longrightarrow} \underset{\mathrm{R}_{2}}{\stackrel{\mathrm{R}_{2}}{\mathrm{~T}_{1}}} \mathrm{OH}
\end{aligned}
$$

Scheme 2. Preparation of ketones and tertiary alcohols by reacting organolithium compounds with lithium carboxylates.
For instance, in the asymmetric LDA-mediated synthesis of the anticancer Lonafarnib 8, a unique water effect on the enantioselectivity was discovered. In the key alkylation step, an LDA-THF complex in cyclohexane was added to a toluene solution containing the tricyclic substrate $\mathbf{6}$, the chiral norephedrine-based mediator, and the alkylating agent 7 . Counter-intuitively, the highest ee $(95 \%)$ and the best yield $(95 \%)$ in 8 were achieved once one equivalent of water was sequentially added to the above reaction mixture, then compensated by an additional equivalent of LDA. In the absence of water, both the ee and the yield in $\mathbf{8}$ dramatically dropped down to $50 \%$ (Scheme 3). ${ }^{[12]}$ As an additional example, carboalumination of alkynes has been proved to occur within minutes at $-23^{\circ} \mathrm{C}$ (and is fast even at $-70^{\circ} \mathrm{C}$ ) in the presence of stoichiometric amounts of water leading stereoselectively to alkenes. ${ }^{[13]}$ To understand this water effect is extremely important to study the interaction of water with organometallic compounds.
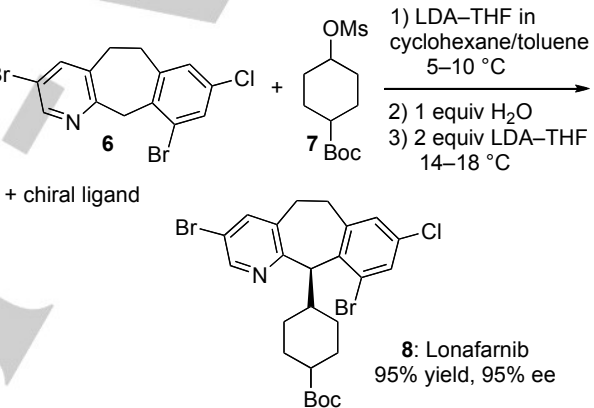

Scheme 3. Stereoselectivity achieved in the key alkylation step by adding water.

We have always been taught about the crucial role played by water in Life Sciences. Among its properties, it is worth mentioning its extraordinary capability to engage in strong intermolecular hydrogen bonding with a plethora of Lewis acid and basic sites, thereby promoting a self-organization in supramolecular ordered structures. Could the water play a similar role in organometallic compounds? Careful, systematic, and controlled hydrolysis studies performed by Roesky and coworkers of kinetically stabilised Group 13 trialkyl compounds, supported by spectroscopic and crystallographic evidences, have led to the isolation and the structural characterization of interesting intermediate oligomeric compounds that eventually result in final policondensed metalloxane clusters. ${ }^{[14]}$ More recent work disclosed the synthesis of organoaluminum hydroxides [15] and of three-in-one clusters ${ }^{[16]}$ comprising two tetranuclear aluminophosphate units and a tetrameric alumino hydroxide unit. These examples testify that water plays a major role also in organometallic chemistry contributing to the coordination sphere of the metal, and promoting intermolecular interactions and extensive self-assembly.

What about the "role of water" in the reactions of organometallic compounds of s-block metals? The hydrolysis of organolithium compounds by water or other proton donors is often assumed to be a very simple process yielding 
quantitatively the corresponding organic acid and $\mathrm{LiOH} .{ }^{[17]}$ As a matter of fact, it may not be as simple as is commonly believed. The rate of protonation of $\mathrm{Et}_{2} \mathrm{O}$ solution of $\mathrm{PhLi}$ and $\mathrm{PhCH}_{2} \mathrm{Li}$ and their $\mathrm{O}$-deuteriated analogues by water or alcohols, for instance, shows small isotope effects (1.0-1.5), which implies that the rate-determining step is the displacement of $\mathrm{Et}_{2} \mathrm{O}$ from the organolithium compound by the oxygen of the "acid". ${ }^{[18]}$ Could water act as a polar ligand towards $\mathrm{Li}^{+}$centres? The first lithiated organic compound containing water as a ligand was published by Wright and co-workers. ${ }^{[19]}$ Lithiation of 2mercaptobenzoxazole, in the presence of $N, N, N^{\prime}, N^{\prime}$ tetramethylethylenediamine (TMEDA) and $\mathrm{H}_{2} \mathrm{O}$ (both adventitious and deliberately added to the reaction mixture), produced the monomeric complex 9 (Figure 1) exibiting a strong hydrogen bonding between one proton of the coordinated $\mathrm{H}_{2} \mathrm{O}$ and the polarised sulfur centre of the organic anion, rather than a protonated $\mathrm{Li}-\mathrm{OH} \cdots \mathrm{SH}$ species.

Such a molecular structure, as suggested by the authors, can be viewed as a model for how hydrolysis of organolithium compounds might take place. Analogously to what has been ascertained in the case of organoalanes, ${ }^{[14]}$ this process might proceed as well via preliminary organolithium-water complex formation followed by proton transfer to the carbanion.

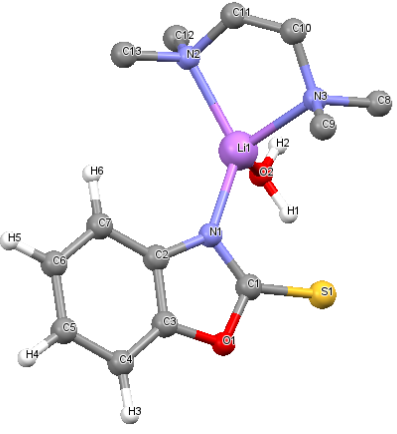

Figure 1. Molecular structure of the complex (9) between lithiated 2mercaptobenzoxazole and TMEDA.

The relative rate of these processes, however, might also be influenced by the nature of the aggregate involved because of the strong structure-reactivity relationship in organolithium compounds. ${ }^{[5 b, c]}$ These findings were then also extended to alkaline-earth metal complexes, ${ }^{[20]}$ with the synthesis of aqua complexes carried out by "assembling" $\mathrm{H}_{2} \mathrm{O}$ ligands via solid metal hydroxides in a hydrocarbon solvent and in the presence of a Lewis base.

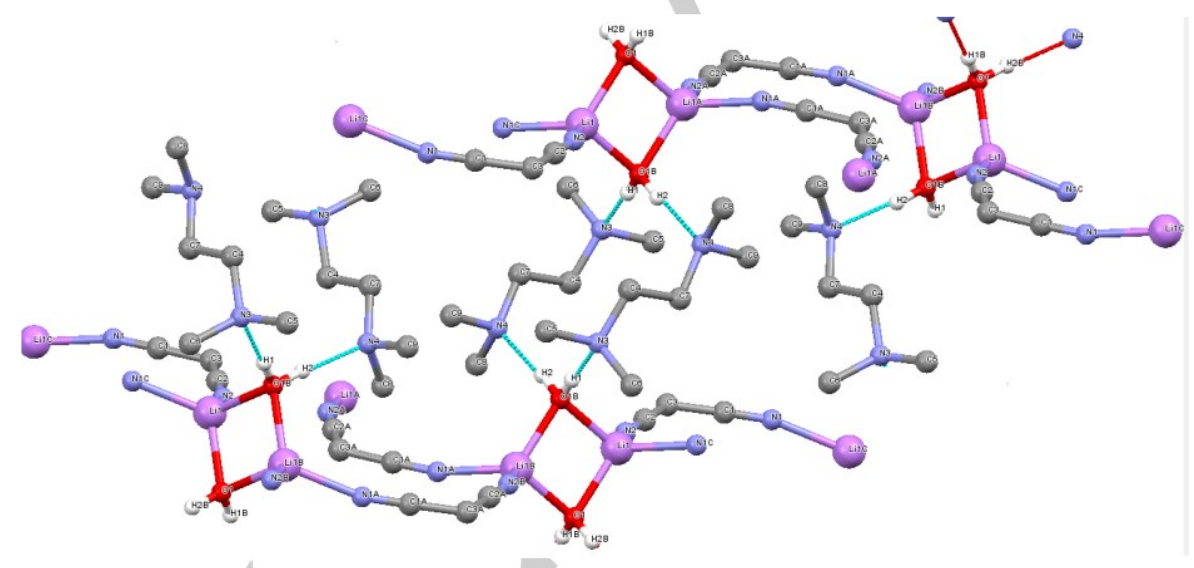

Figure 2. Molecular structure of the 1:1:1 complex (10) among lithiated malonodinitrile, TMEDA, and $\mathrm{H}_{2} \mathrm{O}$.

The first structural characterisation of an $\mathrm{H}_{2} \mathrm{O}$-containing complex of the lithium salt of an organic molecule containing an acidic $\mathrm{C}-\mathrm{H}$ bond was also reported. ${ }^{[21]}$ The three-dimensional polymeric structure 10 depicted in Figure 2 discloses an intriguing complex of lithiated malonodinitrile, TMEDA, and $\mathrm{H}_{2} \mathrm{O}$ in a 1:1:1 molar ratio. What is remarkable here is $(a)$ the lack of TMEDA-Li interactions which is unprecedented in lithium chemistry especially considering that TMEDA is a bidentate ligand compared to water, which should favor complexation to lithium, and (b) the ability of each water molecule to engage simultaneously in hydrogen bonding to two TMEDA molecules (donor function) and to two lithium atoms (acceptor function) (Figure 2).

The intrinsic reactivity of a series of monomeric allylmetals with water and carbonyl compounds has been recently addressed by a theoretical study. ${ }^{[22]}$ Interestingly, calculations suggest that intrinsic kinetic preference of allylation over hydrolysis correlates quite well with the reactivity of hydrolysis. That is, a higher activation energy of hydrolysis corresponds to a higher kinetic preference toward allylation. However, the sole polarity of the $\mathrm{C}-\mathrm{M}$ bond does not fully account for the reactivity of hydrolysis, but both nucleophilicity of the allylmetal and thermodynamic driving forces are likely significantly to contribute to the barrier of hydrolysis. Data relative to the organometallic compounds of the s-block elements also suggest that both $\pi$ complexes of $\mathrm{Li}$ and polarised $\sigma$-complexes of $\mathrm{MgBr}_{2}$ may hydrolise or allylate preferentially, depending on the employed experimental conditions. In particular, calculations for the reaction of allylMgBr with water and acetone show that both activation energies of hydrolysis $(4.5 \mathrm{kcal} / \mathrm{mol})$ and allylation $(5.7$ $\mathrm{kcal} / \mathrm{mol}$ ) are quite similar. This competition was later experimentally investigated by Madsen and Holm. ${ }^{[23]}$ When 
allylMgBr was reacted with either acetone or $\mathrm{PhCHO}$ in the presence of water (inverse addition), the yields of the corresponding addition products were found to be 91 and $75 \%$, respectively. Grignard reagents are complex mixtures of the Schlenk components alkyl(aryl)magnesium halide, dialkyl(diaryl)magnesium, and magnesium halide salt, solvated by an ethereal solvent, and undergoing very fast chemical exchange in solution (Scheme 4). ${ }^{[5 \mathrm{~g}]}$

$$
2 \mathrm{RMgBr} \rightleftarrows \mathrm{R}_{2} \mathrm{Mg}+\mathrm{MgBr}_{2}
$$

Scheme 4. The Schlenk equilibrium.

The position of the equilibrium is influenced by solvent, temperature, and the nature of the substituents. It is shifted left to right in strongly donating solvents (e.g., THF or dioxane) because the stabilization due to the interaction with solvent molecules decreases in the order: $\mathrm{MgX}_{2}>\mathrm{RMgX}>\mathrm{R}_{2} \mathrm{Mg}$, that is according to the Lewis acidity of the various components ${ }^{[24]}$ Thus the above results would seem to indicate that water preferentially coordinates magnesium, the complexation energy with one water molecule being $-23.1 \mathrm{kcal} / \mathrm{mol}{ }^{[22]}$ It may be that "coordinated" water is less reactive in the protonation reaction, thereby allowing the addition reaction to take place more competitively. A possible "scavenging" effect toward water promoted by any electrophilic magnesium compound present in solution was supported by an experiment in which allyl $\mathrm{MgBr}$ was added to a mixture of acetone-water in the presence of an extra $\mathrm{MgBr}_{2}$. In this case, the yield of the addition product was quantitative. Benzylmagnesium chloride also proved to react sufficiently faster with acetone and benzaldehyde rather than being quenched with water, whereas butylmagnesium bromide yielded only traces of the expected addition products.

During the investigation of the directing ability of the tetrahydrofuranyl moiety in promoting regioselective ortholithiation/functionalisation of diaryltetrahydrofurans, an unexpected reactivity was observed by Capriati and co-workers in screening for electrophiles. ${ }^{[25]}$ While no reaction was detected upon adding acetone to a dry- $\mathrm{Et}_{2} \mathrm{O}$ solution of the putative ortholithiated intermediate 11- $\mathrm{Li}$ (generated via lithiation of the parent precursor $11-\mathrm{H}$ with $t$-BuLi at $0{ }^{\circ} \mathrm{C}$ for $10 \mathrm{~min}$ (direct addition)), the expected hydroxyalkylated adduct 12 could instead be isolated in $30 \%$ yield once an $\mathrm{Et}_{2} \mathrm{O}$ solution of $11-\mathrm{Li}$ was added over an acetone-water mixture (6 equiv each) at room temperature (inverse addition). It was ascertained, however, that water apparently did not boost any "rate acceleration" of the reaction as a similar yield was obtained in neat conditions, that is in the absence of water, which simply acts as a bystander (Scheme 5). The employment of cyclopentyl methyl ether (CPME) as an alternative environmentally friendly reaction medium considerably increased the yield of some adducts (e.g., Etl: $0 \%\left(\mathrm{Et}_{2} \mathrm{O}\right), 80 \%$ (CPME); $\mathrm{Ph}_{2} \mathrm{CO}: 40 \%\left(\mathrm{Et}_{2} \mathrm{O}\right), 90 \%$ (CPME); 4- $\mathrm{ClC}_{6} \mathrm{H}_{4} \mathrm{CHO}: 40 \%$ ( $\mathrm{Et}_{2} \mathrm{O}$ ), 80\% (CPME); $\mathrm{Ph}_{2} \mathrm{PCl}: 60 \%\left(\mathrm{Et}_{2} \mathrm{O}\right.$ ), $85 \%$ (CPME)), but again 12 was isolated with a yield not higher than $30 \%$ (direct addition), enolization most probably still competing a lot with nucleophilic addition.

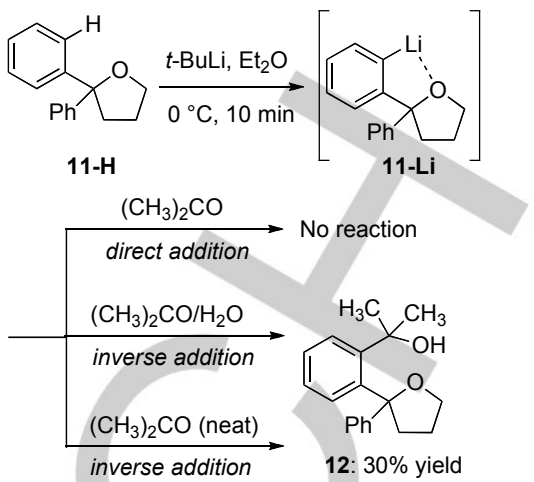

Scheme 5. ortho-Lithiation/functionalisation of diphenyltetrahydrofuran with acetone.

The potential impact of protic solvents in the above functionalisations was further investigated employing the socalled "deep eutectic solvents" (DESs). The concept of DES was firstly introduced by Abbott and co-workers to describe the formation of a liquid eutectic mixture $\left(\mathrm{mp} 12{ }^{\circ} \mathrm{C}\right)$ starting from two solid materials with high melting points: choline chloride $\left(\mathrm{ChCl}, \mathrm{mp} 133{ }^{\circ} \mathrm{C}\right)$ and urea $\left(\mathrm{mp} 302{ }^{\circ} \mathrm{C}\right)$ in a ratio $1: 2$ (1ChCl/2Urea). ${ }^{[26]}$ DESs are today generally defined as combinations of two or three safe and inexpensive components which are able to engage in hydrogen bond interactions with each other to form an eutectic mixture with a melting point lower than either of the individual components. ${ }^{[27]} \mathrm{ChCl}$, in particular, is nowadays one of the widespread ammonium salt used for the synthesis of DESs. The latter (also known as vitamin $\mathrm{B}_{4}$ ) is produced on the scale of million metric tons per year (ca. $2 € / \mathrm{Kg}$ ) as an additive for chicken feed and has many other applications Thanks to their low ecological footprint and attractive low price, $D E S s$ have now become of growing interest both at academic and industrial levels especially for their unusual solvent properties. It is worth noting that the concept of DESs is quite different from that of traditional ionic liquids (ILS) (vide infra) because the former are not entirely composed of ionic species, and can also be obtained from non-ionic species. ${ }^{[27]}$

Both nucleophilic additions and substitutions proved to be effective in such eutectic mixtures providing the expected adducts in good yields and competitively with protonolysis. ${ }^{[25]}$ Adduct 12, for example, could now be recovered with a yield of $40 \%$ upon adding an $\mathrm{Et}_{2} \mathrm{O}$ solution of 11- $\mathrm{Li}$ to acetone (6 equiv) in a ChCl-Gly (1:2) eutectic mixture at room temperature and under air (Scheme 6). Similarly, the addition reaction of a CPME solution of 11-Li to benzophenone, run either in a ChCl-Gly (1:2) or in a ChCl-urea (1:2) DES mixture, gave the hydroxyalkylated compound 13 in both cases in $75 \%$ yield. Chlorodiphenylphosphine also successfully underwent nucleophilic substitution in $\mathrm{ChCl}$-urea (1:2) leading the phosphenyl derivative 14 in $75 \%$ yield. Remarkably, once a commercial pentane solution of $t$-BuLi (1.9 equiv) was rapidly spread out over a mixture of 11-H (1 equiv) in CPME and $\mathrm{ChCl}-$ Gly (1:2), at $0{ }^{\circ} \mathrm{C}$, under air, and under vigorous stirring, and quenched after 1 min reaction time with neat DMF (2 equiv), the formylated adduct 15 could be isolated in $90 \%$ yield (Scheme 6). 


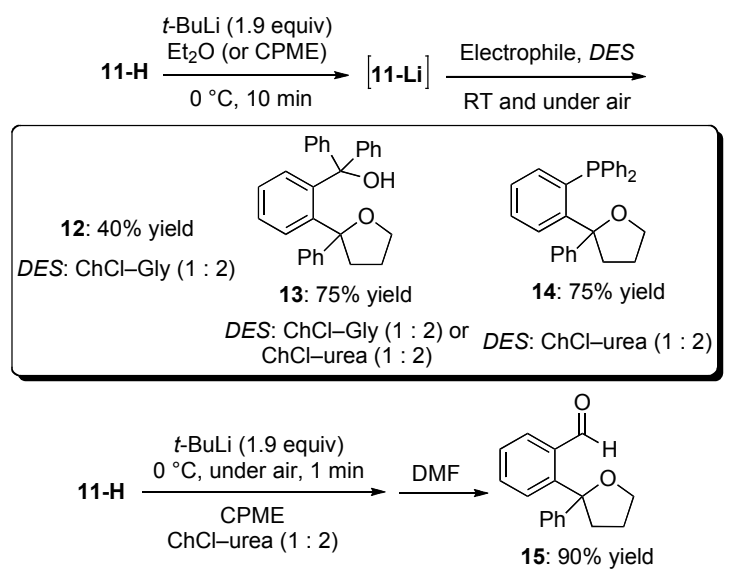

Scheme 6. Regioselective preparation of adducts 12-15 via ortholithiation/electrophilic interception of 11-H in DES mixtures.

o-Tolyl-substituted tetrahydrofuran derivatives $16-\mathrm{H}$ have been recently found to undergo an unprecedented highly regioselective intramolecular $\mathrm{C}-\mathrm{O}$ bond breaking reaction, triggered by the corresponding laterally lithiated intermediates 16- $\mathbf{L} \mathbf{i}$, ending up with the formation of functionalised primary alcohols 17 showing incorporation in their skeletons of both a second equiv of base and of an electrophile (if any) at a tertiary carbon atom (Scheme 7). ${ }^{[28]}$

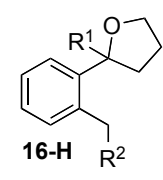

$$
\begin{aligned}
& \stackrel{\mathrm{R}^{3} \mathrm{Li} \text { (1 equiv) }}{0^{\circ} \mathrm{C}, \text { under air }} \\
& \underset{\mathrm{ChCl} \text {-Gly }(1: 2)}{\longrightarrow}
\end{aligned}
$$

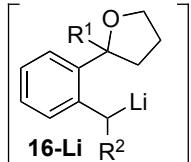
$\mathrm{R}^{3} \mathrm{Li}$ (1 equiv)

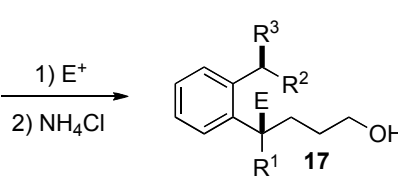

Scheme 7. Site-selected lateral lithiation/ring-opening of $\mathbf{1 6 - H}$ and the regioselective preparation of functionalised alcohols 17 via intermediates $16-\mathrm{Li}$.

This novel organic transformation can be also conveniently run directly in a glycerol-containing eutectic mixture, as a benign reaction medium, competitively with protonolysis. As a general reaction procedure, a commercial hydrocarbon solution of the organolithium ( $s-\mathrm{BuLi}, \quad i-\mathrm{PrLi}, t-\mathrm{BuLi}$ ) was added by rapidly spreading it out over a mixture of 16-H in CPME and ChCl-Gly (1:2), at $0{ }^{\circ} \mathrm{C}$, under air, and under vigorous stirring, and quenched after $3 \mathrm{~min}$ reaction time with the electrophile to give alcohols 17 in yields up to $>98 \%$. The scope, limitation, and mechanistic aspects of this reaction, which pioneers "greener" alkylative THF ring-opening processes, have been discussed. ${ }^{[28]}$ Interestingly, $s$-BuLi was found to promote a faster deprotonation compared to $t$-BuLi, and ortho-lithiation seriously competes with lateral lithiation only in the case of substrates possessing an ethyl group in an ortho position at one of the two aromatic rings.
The chemoselective nucleophilic addition of organolithium and Grignard reagents to ketones in $\mathrm{ChCl}$-based eutectic mixtures was in depth investigated by Hevia, García-Álvarez and co-workers. ${ }^{[29]}$ A range of the above reagents (19) could successfully be added, under air and at room temperature, to aromatic and aliphatic ketones 18 in both $\mathrm{ChCl}-\mathrm{Gly}(1: 2)$ and $\mathrm{ChCl}-\mathrm{H}_{2} \mathrm{O}(1: 2)$ mixtures, thereby affording the corresponding tertiary alcohols $\mathbf{2 0}$ in good yields (up to $90 \%$ ) and competitively with protonolysis (Scheme 8).

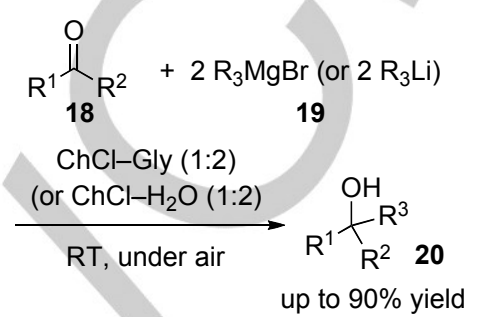

Scheme 8. Chemoselective addition of Grignard and organolithium reagents to ketones in $\mathrm{ChCl}$-based eutectic mixtures.

A comparison of the reactivity profiles of these organometallic reagents in DESs with those in pure water, suggest that a kinetic activation takes place in the former most probably due to the formation of more nucleophilic halide-rich magnesiate or lithiate species further to the reaction of the alkylating reagent with $\mathrm{ChCl}$. Thus, $\mathrm{ChCl}$ may be playing a double role in these processes, that is as a component of both the DES mixtures and the new "ate" complexes. This conclusion was supported by X-ray crystallographic studies, multinuclear magnetic resonance investigations, and ${ }^{1} \mathrm{H}$ DOSY NMR experiments.

In a recent paper, Song showed as well that catalytic amounts of $\mathrm{NBu}_{4} \mathrm{Cl}$ in THF solutions of Grignard reagents enhanced the efficiency of addition reactions to carbonyl compounds producing tertiary alcohols in excellent yields, while minimizing the formation of enolization and reduction products ${ }^{[30]}$ The authors proposed that the presence of this ammonium salt should help to shift the Schlenk equilibrium of Grignard reagents in solution (Scheme 4) to the side of the dimeric species that would favour the addition reaction thanks to the 2:1 complex involved in the six-membered transition state.

\subsection{Reactivity in ionic liquids}

Generally, the term "ionic liquids" (ILs) stands for liquids composed of poorly coordinated ions with a melting point below $100{ }^{\circ} \mathrm{C} .{ }^{[31]}$ At least one ion has a delocalised charge, and one component is organic, which prevents the formation of a stable crystal lattice. They have recently attracted great interest as "greener" alternative to conventional organic solvents because of their thermal stability, non-flammability, easy of recycling, low vapour pressure, and catalytic properties. ${ }^{[32]}$ Their use as solvents for reactions involving organometallic compounds of $\mathrm{s}$ block elements, however, is still in its infancy. One of the most extensively studied class of $I L s$ is based on imidazolium cations with an appropriate counter anion ( $I m / L s)$, which are known to support many organic transformations. ${ }^{[32]}$ Because of an acidic 
hydrogen substituent at the C-2 position, Im/Ls (21) have been shown to react under basic conditions to produce $\mathrm{N}$-heterocyclic carbenes (NHCs) (22), which are neutral, highly reactive, sixelectron species possessing a dicoordinate carbon atom with two nonbonding electrons, and are responsible of many side reactions (Scheme 9).<smiles>[R]n1cc[n+]([Y])c1CCCCCCC</smiles>

Scheme 9. Formation of a NHC (22) species from an imidazolium cation (21).

This problem was overcome by Clyburne and co-workers who showed that dried phosphonium ILs $\mathbf{2 3}$ are inert towards reactions with strong bases and are not reduced even by potassium metal, thereby representing the first suitable solvents for Grignard chemistry. ${ }^{[33]}$ Commercially available THF solutions of $\mathrm{PhMgBr}$, once dissolved in 23 (ratio THF : $23=1: 3$ ), proved to cleanly promote carbonyl additions, benzyne reactions, halogenation, hydroxy(alkylation)arylation, and coupling reactions. Most importantly, competitive deprotonation of $\mathbf{2 3}$ to produce the phosphorane $\mathbf{2 4}$ did not take place (Scheme 10). The inertness of phosphonium cations towards Grignard solutions appears to have primarily a kinetic basis and to be anion dependent: small bases are more prone to deprotonate $\mathbf{2 3}$ whereas large bases are more reluctant. Several other causes, however, seem also to contribute to such an inertness; e.g., the bulkiness and the flexibility nature of the cation as well as its electrochemical robustness compared to unsaturated ions. ${ }^{[34]}$
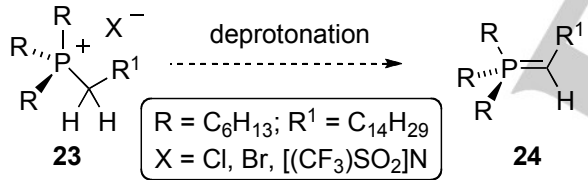

Scheme 10. Possible formation of phosphorane $\mathbf{2 4}$ by deprotonation of $\mathbf{2 3}$

The introduction of an ether oxygen on the side arm of a phosphonium salt (25) contributes to stabilising the organomagnesium reagent, thereby improving the capability of the corresponding $I L$ to act as a solvent even for aliphatic Grignard reagent-mediated reactions (Figure 3). ${ }^{[35]}$

$$
\begin{gathered}
\mathrm{R}=\mathrm{Bu}, \mathrm{X}=\mathrm{Tf}_{2} \mathrm{~N} \\
\mathrm{R}=n \text {-octyl, } \mathrm{X}=\mathrm{Tf}_{2} \mathrm{~N}
\end{gathered}
$$

Figure 3. Phosphonium ILs with an ether functionality.

Walsby and co-workers also demonstrated that while in molecular solvents Grignard reagents react according to nucleophilic pathways, ILs are ideal reaction media to promote electron-transfer processes. ${ }^{[36]}$ The Kumada-Corriu reaction, which involves the coupling of Grignard reagents with aryl halides mediated by transition metal catalysts (typically nickel or palladium), has been successfully carried out between $\mathrm{PhMgBr}$ and aryl halides in the phosphonium IL 26 in the presence of a $\mathrm{Ni}(0)$ complex of NHC 27 to afford biaryl derivatives 28 with yields up to $88 \%$, thereby supporting the in situ generation of carbene species (Scheme 11). Remarkably, such a reaction even facilitates the activation of $\mathrm{C}-\mathrm{F}$ bonds.

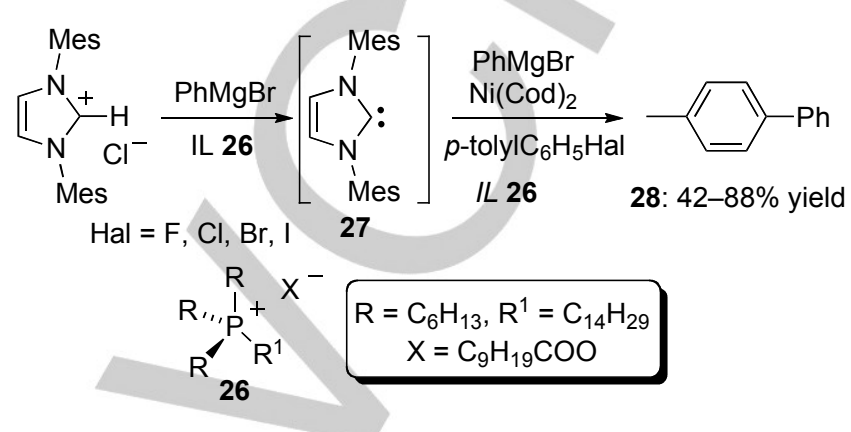

Scheme 11. Kumada-Corriu cross-coupling reaction in the phosphonium $I L$ 27.

Apart from phosphonium ILs, also some imidazolium-based ILs can withstand the strong basicity of the Grignard reagents. These include ImILs with a phenyl substituent ${ }^{[37]}$ and with an isopropyl group ${ }^{[38]}$ at the vulnerable C-2 position. Both ILs 29 and 30 (Figure 4) have been successfully employed as suitable solvents in reactions involving the addition of aliphatic and aromatic Grignard reagents to aldehydes, ketones and esters affording the expected hydroxyalkylated adducts in good yields (68-83\%). These $I m / L s$ can be recycled and reused several times without appreciable loss of the same IL. All attempts, however, to generate Grignard reagents in ILs failed. In 2006, Chan and co-workers reported the first example of an organomagnesium species generated directly in the pyridiniumbased IL $\mathbf{3 1}$ having a tetrafluoroborate as a counter ion (Figure 4). ${ }^{[39]}$ The reactivity pattern showed towards carbonyl compounds for reactions run in $\mathbf{3 1}$, however, was different from that exhibited by Grignard reagents in conventional organic solvents, the yields in the final adducts also being critically dependent on the molar ratio of the reagents and the presence of additives in the reaction mixture. New alkylpyridinium (32) and tetralkylphosphonium (33) ILs, possessing an ether functionality to provide stabilisation to the Grignard reagent, have been prepared by Scammells and co-workers and evaluated as solvents for Grignard reactions. ${ }^{[40]}$ Interestingly, different outcomes have been observed according to the presence or not of an ethereal co-solvent. When the addition reaction to carbonyl compounds was run in ILs 32, the expected adducts occurred only in the presence of $\mathrm{Et}_{2} \mathrm{O}$, whereas in the absence of this ether an unusual reduction of aldehydes to the corresponding primary alcohols was favoured. On the other hand, aldehydes cleanly reacted with Grignard reagents in ILs $\mathbf{3 3}$ affording the corresponding addition products only in the presence of $\mathrm{Et}_{2} \mathrm{O}$ as a co-solvent. 
<smiles>CN1CC[N+]([N+](=O)[O-])=C1P</smiles><smiles>CC(C)C1=[N+](Br)CCN1C</smiles>

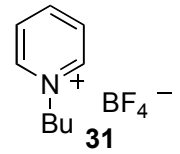<smiles>[R]OCc1ccc[n+](C=[Co])c1</smiles>

$$
\underset{33}{\left(\mathrm{C}_{8} \mathrm{H}_{17}\right)_{3} \mathrm{P}} \stackrel{+}{\mathrm{O}^{\mathrm{O}}} \underset{\mathrm{NTf}_{2}{ }^{-}}{-}
$$

Figure 4. ILs employed as alternative reaction media for Grignard reagents.

To the best of our knowledge, analogous reactions of organolithium compounds run in ILs always produced decomposition and unidentified products. Because of the broad use of organolithium and Grignard reagents in the pharmaceutical and fine chemical industry, a judicious choice of the reaction solvent is crucial from both safety and environmentally standpoints. In this context, 2-MeTHF (derived from a renewal source) and CPME (directly obtainable from cyclopentene) are emerging "greener" alternatives for organometallic reactions to the common $\mathrm{Et}_{2} \mathrm{O}$ and $\mathrm{THF}$, and have also proved to be more effective in improving product yield and in suppressing side reactions. ${ }^{[11]}$ The challenge will be the use of commercially prepared Grignard and organolithium solutions directly in the above solvents.

\section{Organometallic compounds of d-block elements}

As has been assessed in the Introduction, OC has become a cornerstone of modern organic synthesis, and nowadays hardly any total synthesis endeavour can be envisioned without a key step involving the use of polarised organometallic compounds containing d-block elements, that is the transition metals. ${ }^{[42]}$ These fundamental reagents (most commonly organozinc and organocopper compounds) are able to deliver carbon residues (M-C bonds) from zinc ${ }^{[43]}$ or copper ${ }^{[44]}$ to carbon halides or pseudohalides $(C-X)$, to form new $C-C$ bonds. However, the chemoselectivity of these processes can be seriously compromised by: i) the formation of undesired products, ii) the use of low temperatures (ranging from 0 to $-78^{\circ} \mathrm{C}$ ), and iii) the employment of dry and hazardous ethereal solvents, and inert atmosphere protocols (to avoid fast degradation of the polar reagents). All these experimental restrictions hinder the synthetic application of these polarised species under environmentally-friendly reactions conditions (i.e. at room temperature and in the absence of protecting atmosphere), $[1,3,45]$ and their use in the presence of unconventional solvents [e.g., water, ILs, supercritical $\mathrm{CO}_{2}\left(\mathrm{scCO}_{2}\right)$ or perfluorinated solvents] as reaction media. ${ }^{[46]}$ Despite all these drawbacks, during the last decades the chemistry of polarised organometallic compounds containing d-block elements has crossed the frontiers between their application in modern synthetic organic chemistry and the growing area related to the employment of unconventional solvents. Since the synthesis of the first polarised organozinc compound $\left(\mathrm{ZnEt}_{2}\right)$ by Wanklyn in $1848,{ }^{[47]}$ it is well-known that these basic compounds are able to react with several unconventional solvents (like water or $\mathrm{scCO}_{2}$ ).

This Section covers the progress made in the application of the aforementioned unconventional solvents as reaction media in a variety of organozinc-, organocopper-, and organogold-mediated organic reactions. In particular, the following reactions will be surveyed: i) Reformatsky- and Barbier-type reactions, ii) addition of organozinc derivatives to $\alpha, \beta$-unsaturated carbonylic compounds, iii) cross-coupling reactions of the in situ generated organozinc reagents and organic halides (Negishi coupling), iv) polymerization reactions, v) organogold reactions, and vi) iridium-promoted $\mathrm{C}-\mathrm{H}$ bond activation reactions.

\subsection{Reformatsky reaction in unconventional solvents}

The Reformatsky reaction, ${ }^{[48]}$ which involves the treatment of a haloester with a carbonyl compound (ketone or aldehydes) in the presence of $\mathrm{Zn}$ (Scheme 12), was the first example of addition of polarised organometallic reagents containing d-block elements to carbonyl compounds. Since its discovery in the $19^{\text {th }}$ century, it was believed that this $\mathrm{Zn}$-mediated addition reaction could only take place under protective atmosphere (using Schlenk techniques) and employing dry organic solvents. ${ }^{[49]}$ However, several examples were then reported in the literature showing the reactions between carbonyl compounds and organic halides, mediated by reactive d-block metals $(\mathrm{Zn}, \mathrm{Cu})$, in both wet solvents and pure water. ${ }^{[50]}$

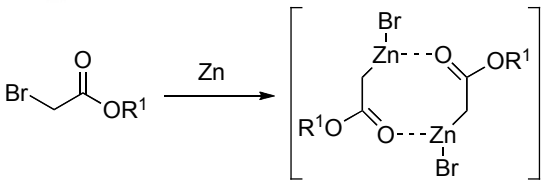

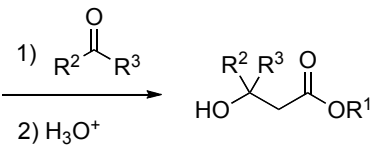

Scheme 12. Reformatsky reaction between haloesters and carbonyl compounds in the presence of $\mathrm{Zn}$.

In 1990, Chan, Li and co-workers lighted the way by studying the direct Reformatsky-type conversion between benzaldehyde and $\alpha$-bromopropiophenone in pure water as the solvent mediated by metallic zinc (Scheme 13). ${ }^{[51]}$ Both the yield (82\%) and the ratio of the two diastereomeric products $(\mathbf{3 4}, 2.5: 1$ erythro:threo) gathered in this aqueous reaction are comparable to those obtained with preformed organometallic reagents under anhydrous conditions. Latter, Bieber and co-workers demonstrated that this pioneering idea could be extended to a wide variety of carbonyl substrates (including aromatic and aliphatic aldehydes and ketones) and to different haloesters. ${ }^{[52]}$ Again, yields achieved under these aqueous conditions proved to be comparable to the ones obtained in anhydrous organic solvents. Chan and co-workers proposed that this reaction may follow a radical mechanism (Single Electron Transfer), as no 
formation of the desired product was observed in the presence of galvinoxyl or hydroquinone (radical scavengers). ${ }^{[51 \mathrm{~b}]}$

$$
\text { }
$$

ratio erythro:threo $=2.5: 1$

Scheme 13. Reformatsky-type reaction between benzaldehyde and $\alpha$ bromopropiophenone in water.

Not only water, but also other unconventional solvents like ILs have been employed as reaction media for Reformatsky-type reactions. As previously discussed in Section 2.2 of this Microreview, ILs have received much attention as a new class of unconventional solvents during the last decades. ${ }^{[32]}$ To the best of our knowledge, the first Reformatsky reaction in a variety of ILs was reported by Kitazume and co-workers (Scheme 14). ${ }^{[53]}$ The authors studied the Reformatsky reaction: i) between aromatic, aliphatic or alkenyl aldehydes (35) with different haloesters (36), ii) mediated by metallic $\mathrm{Zn}$, and iii) in the ILs [EtDBU][OTf] (8-ethy-1,8-diazabicyclo[5,4,0]-7-undecenium trifluoromethanesulfonate), [BMIM][BF 4 (1-Butyl-3methylimidazolium tetrafluoroborate), and [BMIM] $\left[\mathrm{PF}_{6}\right]$ (1-Butyl3-methylimidazolium hexafluorophosphate). At room temperature, only a moderate yield $(52 \%)$ of the desired compound $\mathbf{3 7}$ was achieved in the $I L$ [EtDBU][OTf]. However, upon heating the reaction to $50{ }^{\circ} \mathrm{C}$, almost quantitative conversion (93\%) in $\mathbf{3 7}$ was reached. As has been pointed out in Section 2.2, one of the major advantages associated with the use of $I L s$ as solvents is the possibility of reusing the $I L$ by a simple extraction of the desired organic product (37) with organic solvents. ${ }^{[32,46]}$ In this way, the $I L$ could be recycled up to three consecutive cycles without any loss of activity or selectivity.

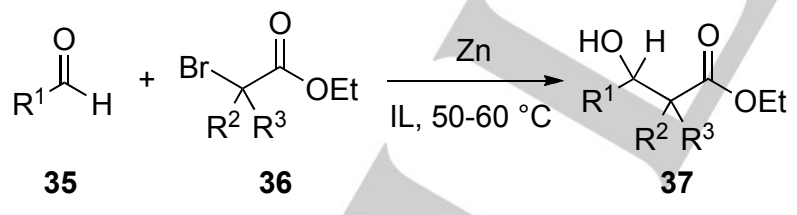

$\mathrm{R}^{1}=\mathrm{Ph}, \mathrm{Ph}\left(\mathrm{CH}_{2}\right)_{2},(E)-\mathrm{PhCH}=\mathrm{CH} ; \mathrm{R}^{2}=\mathrm{R}^{3}=\mathrm{H}, \mathrm{F}$

Scheme 14. Reformatsky reaction in ILs

\subsection{Barbier reaction in unconventional solvents}

The Barbier reaction, ${ }^{[54]}$ which involves the reaction of organic halides and carbonyl compounds in the presence of magnesium, aluminium, zinc, indium, tin or its salts is one of the most important methods for creating $\mathrm{C}-\mathrm{C}$ bonds and has widespread synthetic applications in organic chemistry. ${ }^{[55]}$ The reaction proceeds via the nucleophilic attack of the in situ generated organometallic compound on the carbonyl electrophile (generally an aldehyde). Since its discovery, there has been considerable attention towards the development of this $\mathrm{Zn}$-mediated reaction in water ${ }^{[56]}$ In fact, the allylation of aldehydes and ketones under the Barbier conditions usually occurs faster and gives rise to higher yields when water is used as the (co)solvent. ${ }^{[57]}$ In this sense, $\mathrm{Li}$ and Chan reported one of the first and innovative allylation reactions of carbonyl compounds promoted by $\mathrm{Zn}$ in water (Scheme 15). ${ }^{[58]}$ Again, the presence of water was critical to the success of the coupling step for the formation of $\mathbf{3 8}$. Thus, when the reaction was performed in dry conventional ethereal solvents (e.g., $\mathrm{Et}_{2} \mathrm{O}$ or THF), poor formation of compound 38 was encountered.

$$
\mathrm{R}^{1}=\text { Aryl, Alkenyl, Alkyl, Benzyl; } \mathrm{R}^{2}=\mathrm{H} \text {, Alkyl }
$$

Scheme 15. Zn-mediated Barbier reaction in water.

Nowadays, a plethora of Zn-mediated allylation of different electrophiles (e.g., aldehydes, ketones, acetals or dioxolanes) in aqueous conditions is known in the literature, allowing the direct synthesis of homoallylic alcohols under environmentally-friendly reaction conditions. ${ }^{[59]}$ Recently, the spectrum of unconventional solvents available to accomplish this $\mathrm{Zn}$-mediated allylation reaction under green conditions has been enlarged by Leeke and co-workers. These authors reported the employment of subcritical $\mathrm{CO}_{2} / \mathrm{H}_{2} \mathrm{O}\left(30{ }^{\circ} \mathrm{C} / 80\right.$ bar) as a renewable solvent mixture to increase the desired allylation reaction with a variety of aryl aldehydes. ${ }^{[60,61]}$

Not only Zn-mediated allylations, ${ }^{[59]}$ but also propargylations $^{[62]}$ and benzylations ${ }^{[63]}$ of different carbonyl compounds can be conveniently performed in the presence of water. In recent years, $\mathrm{Li}$ and co-workers have expanded the scope of this Barbier-type reaction to the more challenging carbonyl alkylations ${ }^{[64]}$ and arylations $^{[65]}$ with non-activated halides in water. In both the examples cited, the desired aromatic aldehyde suffers the corresponding alkylation or arylation in water, which is mediated by stoichiometric amounts of $\mathrm{Zn}$ dust and catalysed by $\mathrm{InCl}$ or $\left[\mathrm{Rh}(\mathrm{acac})(\mathrm{CO})_{2}\right]$ (acac = acetylacetonate), respectively (Scheme 16). These processes allowed the mild and the straightforward synthesis of benzyl alcohols (39) and aryl methanols (40), thereby unlocking one of the last challenges in the field of Barbier-type reactions in water. 


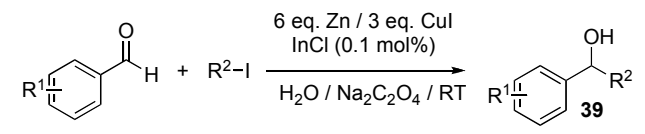

$\mathrm{R}^{1}=\mathrm{H}, p-\mathrm{CN}, p-\mathrm{Cl}, p-\mathrm{Br}, p-\mathrm{CF}_{3}, p-\mathrm{OMe} ; \mathrm{R}^{2}=$ cyclohexyl, $i-\mathrm{Pr}, t-\mathrm{Bu}$

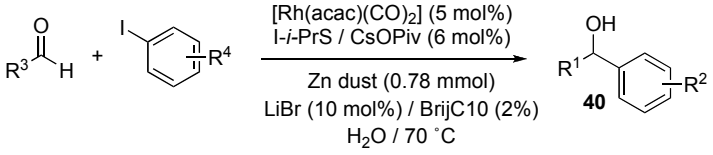

$\mathrm{R}^{3}=$ aryl, alkyl; $\mathrm{R}^{4}=\mathrm{H}, o-\mathrm{Me}, m-\mathrm{Me}, p-\mathrm{Me}, p-\mathrm{CO}_{2} \mathrm{Me}, p-\mathrm{F}, p-\mathrm{Br}$

$$
\underbrace{\mathrm{Cl}^{-}}_{\mathrm{R}=i-\mathrm{Pr}}
$$

Scheme 16. Barbier-type alkylation and arylation of aldehydes in water.

Amines could also be conveniently prepared by direct addition of zinc organometallic reagents to imines in the presence of water. Savoia, Umani-Ronchi and co-workers first developed the enantioselective synthesis of homoallylic amines by addition of in situ generated (allyl) $\mathrm{ZnBr}$ reagents to imines in a mixture of $\mathrm{THF} / \mathrm{H}_{2} \mathrm{O} .^{[66]}$ More recently, Naito and co-workers reported the $\mathrm{Zn}$-mediated addition of alkyl iodides to imines in the absence of VOCs by using a saturated $\mathrm{NH}_{4} \mathrm{Cl}$ aqueous solution as the solvent. ${ }^{[67]}$ Nitrones $\mathbf{4 1}$ can also suffer a Barbiertype alkylation in pure water as the solvent and at room temperature, yielding the corresponding hydroxylamines $\mathbf{4 2}$ (Scheme 17). ${ }^{[68]}$

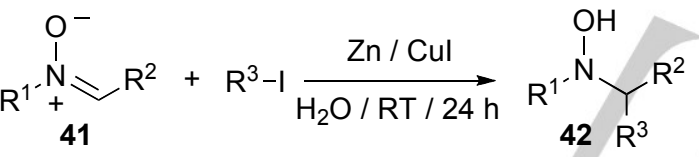

$$
\begin{aligned}
& \mathrm{R}^{1}=\text { aryl, benzyl; } \mathrm{R}^{2}=\text { aryl, alkyl; } \mathrm{R}^{3}=\text { alkyl }
\end{aligned}
$$

Scheme 17. Synthesis of hydroxylamines via Barbier-type alkylation of nitrones in water.

\subsection{Conjugate addition of organozinc derivatives to $\alpha, \beta$ unsaturated carbonylic compounds in water}

The conjugate 1,4-addition of organometallic compounds to electron-deficient olefins represents one of the most powerful tools currently exploited to create new $\mathrm{C}-\mathrm{C}$ bonds. Among the various methods available, the most commonly employed strategies involve the use of organometallic species such as Grignards reagents (RMgX) or organolithium (RLi) compounds. However, the use of these highly reactive organometallic derivatives can lead to undesired side reactions (e.g., Wurtz coupling, reduction of the carbonyl compounds, hydrolysis, competitive 1,2-addition, etc.). ${ }^{[69]}$ Thus, dialkylzinc reagents have dominated the field of copper-mediated enantioselective conjugate addition since their first application in the mid1990s. ${ }^{[70]}$ From that moment on, several reports have appeared in recent years demonstrating that the addition of stoichiometric or sub-stoichiometric quantities of water increases the rate and/or the enantioselectivity of this organic transformation. ${ }^{[71]}$

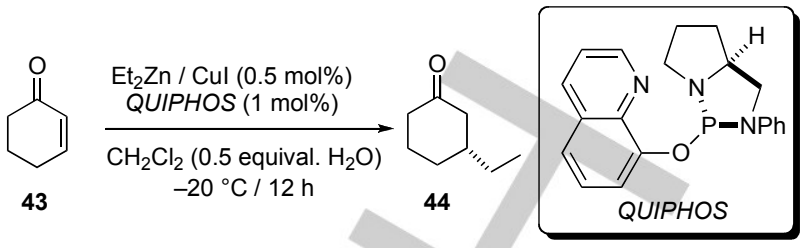

Scheme 18. $\mathrm{Cu}(\mathrm{I})$-catalysed conjugate 1,4 -addition of $\mathrm{Et}_{2} \mathrm{Zn}$ to cyclohexenone (43) accelerated in the presence of water.

Delapierre and co-workers reported the dramatic beneficial effect of addition of water ( 0.5 equiv.) in the asymmetric addition of diethylzinc to cyclohexenone (43) catalysed by $\mathrm{Cul}$ in the presence of chiral ligands (Scheme 18). ${ }^{[72]}$ Thus, when the reaction was performed in dry $\mathrm{CH}_{2} \mathrm{Cl}_{2}$, only $55 \%$ yield of the desired cyclohexanone (44) was achieved in $45 \%$ ee. However, formation of the desired carbonyl compound in higher yield (76\%) and enantiomeric excess (ee 61\%) was observed upon the addition of sub-stoichiometric amounts of water. The authors proposed that the in situ formation of $\mathrm{Zn}(\mathrm{OH})_{2}$ (which is a stronger and more effective Lewis acid), activates the carbonyl moiety. This suggestion was confirmed as the direct addition of $\mathrm{Zn}(\mathrm{OH})_{2}$ to the reaction provided analogous results to those observed with water. ${ }^{[73]}$ Similarly, the addition of substoichiometric amounts of water (0.3-0.33 equiv.) to lithium dimethylcuprate $\left(\mathrm{LiCuMe}_{2}\right)$, generated a more reactive and stereoselective reagent for the conjugate addition to linear $\alpha, \beta$ enones. ${ }^{[7]}$ More recently, Lipshutz and co-workers reported the conjugate addition of in situ generated organocopper reagents to enones $^{[75]}$ in water and at room temperature by using small amounts of commercially available amphiphiles (TPGS-750-M, polyoxyethanyl- $\alpha$-tocopheryl succinate) that are able to form nanomicelles in water.

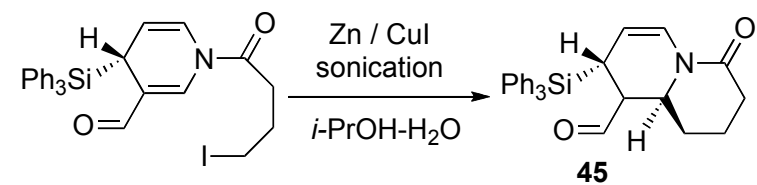

Scheme 19. Synthesis of lupidine analogue 45 mediated by $\mathrm{Zn} / \mathrm{Cul}$ under sonication conditions in the presence of water.

Conjugated 1,4-addition of alkyl halides ( $\mathrm{R}-\mathrm{X})$ to $\alpha, \beta$-unsaturated aldehydes,' ketones, esters, amides, ${ }^{[76]}$ or nitriles ${ }^{[77]}$ can be mediated in $\mathrm{EtOH}-\mathrm{H}_{2} \mathrm{O}$ or $\mathrm{THF}-\mathrm{H}_{2} \mathrm{O}$ mixtures by the combination of $\mathrm{Zn}$ and $\mathrm{Cu}$, under sonication conditions. It is worth noting that this methodology has been fruitfully applied to the synthesis of: i) a variety of vitamin $D_{3}$ derivatives, ${ }^{[78]}$ ii) dioxolanes, ${ }^{[78 d]}$ iii) oxazolidinones, ${ }^{[78 \mathrm{~h}]}$ and iv) sinefungin analogues. ${ }^{[79]}$ Finally, the intramolecular version of this 1,4 addition reaction mediated by $\mathrm{Zn} / \mathrm{Cul}$ allowed the straightforward synthesis of the lupinine analogues 45 (Scheme 19). ${ }^{[80,81]}$ Thus, the 1,4-conjugated addition of alkyl halides to $\alpha, \beta$-unsaturated carbonyl compounds mediated by $\mathrm{Zn}-\mathrm{Cu}$ mixtures in aqueous media proved to be the key step in the total synthesis of a diversity of natural products. 
3.4 Cross-coupling of in-situ generated organozinc reagents with organic halides (Negishi coupling) in unconventional solvents.

Metal-catalysed cross-coupling reactions between an organic electrophile (typically an organic halide) and an organic nucleophile have developed into a standard component of the armamentarium synthetic chemist's toolbox for the formation of C-C and C-heteroatom bonds. ${ }^{[82]}$ Palladium-catalysed reactions, which can be generally carried out under milder conditions and with a wider range of substrates than reactions promoted by other metals, clearly dominate the field. The organic halide can be a $\mathrm{sp}$-, $\mathrm{sp}^{2}$-, or $\mathrm{sp}^{3}$ - hybridised carbon with any halogen or pseudo-halogen leaving group. Different organometallic nucleophiles (e.g., organoboron, organotin, organozinc, organomagnesium) and organic nucleophilic reagents (such as amines, alkenes or alkynes) are routinely used in different cross-coupling reactions. In this Section, the attention will be mainly focused on the Pd-catalysed Negishi coupling (with reference to the cross-coupling reactions of polarised organozinc reagents with organic halides), ${ }^{[83]}$ in different unconventional solvents, like water, ILs and perfluorinated solvents.

Lipshutz and co-workers have almost dominated the field of aqueous Negishi-type cross-coupling reactions by describing a new technology that allows the Pd-catalysed $\mathrm{Zn}$-mediated cross-couplings to be conducted in water and at room temperature, without the need to preform the corresponding organozinc reagent $(\mathrm{RZnX}) .^{[84,85]}$ Lipshutz's approach uses homogeneous micellar catalysis within catalytic nanoreactors formed spontaneously upon dissolution in water of different surfactants (PTS, TPGS, Brij 30, Solutol, SPGS). The scope of this process has been studied in the Pd-catalysed coupling between: i) alkyl halides and aryl or heteroaryl halides (Scheme $20),{ }^{[84 a, f-i]}$ ii) alkyl or benzylic halides and alkenyl halides, ${ }^{[84 b, e, h]}$ and iii) benzyl halides and aryl or heteroaryl halides. ${ }^{[84, d]}$ More recently, Lipshutz and co-workers reported the reduction of alkyl halides, ${ }^{[86]}$ and nitroaromatics ${ }^{[87]}$ in water and at room temperature by using $\mathrm{Zn}$ dust in the presence of nanomicelles composed of the aforementioned surfactants.

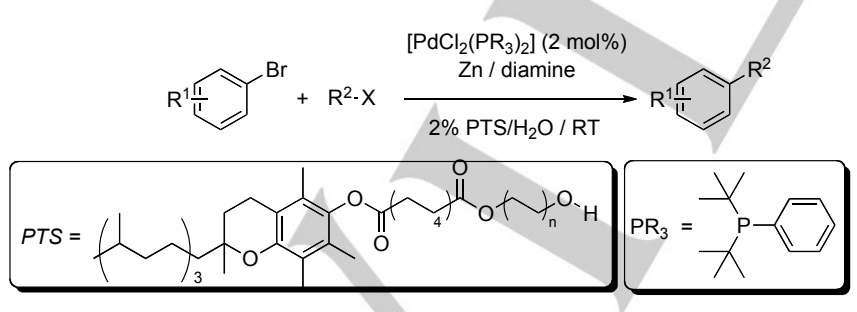

Scheme 20. Representative example of Negishi-type coupling reaction in water at room temperature employing the Lipshutz conditions.

Pd-catalysed Negishi-type reaction has also been reported in ILs. In this regard, Knochel and co-workers described at the beginning of this millennium the cross-coupling reaction between preformed aryl- or benzylzinc halides $(\mathrm{RZnX})$ and various aryl iodides in the $I L \quad\left[\mathrm{BDMIM}^{2}\left[\mathrm{BF}_{4}\right]\right.$ (BDMIM = 1-butyl-2,3dimethylimidazolium), and using as catalytic system the mixture formed by $\left[\mathrm{Pd}(\mathrm{dba})_{2}\right]$ an ionic phosphine 46 (Scheme 21). ${ }^{[88 a]}$ In most cases, the reaction proceeded at room temperature within minutes leading to the desired product in almost quantitative yields. The work up of this reaction is remarkably simple, as the $I L$ phase containing the palladium catalyst can be separated from the organic product simply by extraction with toluene. Attempts to reuse the palladium catalyst showed that after the third cycle, a significant decrease in the yield was observed. The same authors enlarged the scope of unconventional solvents that could be used in the Negishi reaction by describing the Pdcatalysed cross-coupling of organozinc bromides with aryl iodides in perfluorinated solvents. ${ }^{[88 \mathrm{~b}]}$

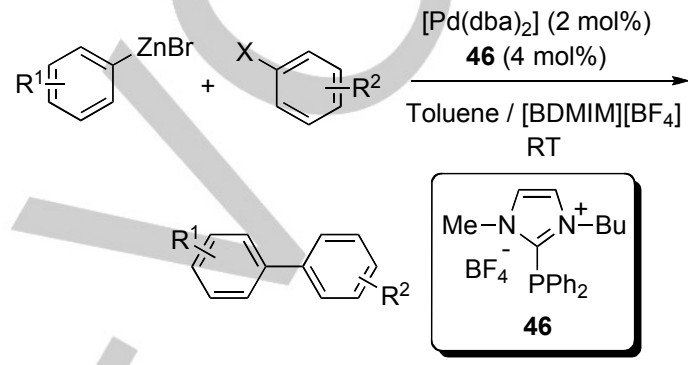

Scheme 21. Pd-catalysed Negishi-type coupling between preformed organozinc reagents and aryl halides in the ionic liquid [BDMIM][BF 4 .

\subsection{Application of lithium organozincates for} chemoselective anionic polymerization

Highly coordinated dianion-type zincates $\left(\mathrm{Li}_{2} \mathrm{ZnR}_{4}\right)$ were reported in the mid-1990s by Uchiyama and co-workers as a new type of zincate complexes, and added a new dimension to organozincate reagents because they were able to promote bromine-zinc exchange and carbozincation reactions. ${ }^{\left[{ }^{[8]}\right.}$ In this regard, the dilithium tetra-tert-butylzincate $\left[\mathrm{Li} 2 \mathrm{Zn}(t-\mathrm{Bu})_{4}\right]$ turned out to be a highly crowded and bulky zincate with an excellent anionic polymerization ability, even in the presence of acidic protons. ${ }^{[90]}$ Uchiyama and co-workers studied the anionic polymerization of $\mathrm{N}$-isopropylacrylamide (NIPAm) using $\mathrm{Li}_{2} \mathrm{Zn}(t$ $\mathrm{Bu})_{4}$ as initiator in both organic solvents and water (Scheme

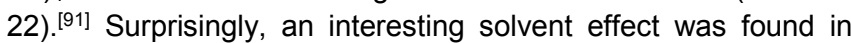
this polymerization reaction: with THF as the reaction medium, only $8 \%$ of the desired polymeric material $\mathbf{4 7}$ was obtained after $24 \mathrm{~h}$, whereas the polymer $\mathbf{4 7}$ could be isolated in high yields $(92-76 \%)$ after 3 hours only when protic solvents (like $\mathrm{H}_{2} \mathrm{O}$ or $\mathrm{MeOH}$ ) were alternatively used. Upon monitoring the time/yields profile of this polymerization reaction in water, the authors noticed that polymer $\mathbf{4 7}$ could be obtained in $92 \%$ yield after 15 minutes. The nature of the organometallic compound proved to be crucial as no polymerization reaction took place when $\mathrm{Li}_{2} \mathrm{Zn}(t-$ $\mathrm{Bu})_{4}$ was replaced by $\mathrm{Lit}-\mathrm{Bu}, \mathrm{ZnCl}_{2}$, $\mathrm{LiCl}$ or $\mathrm{LiOH}$. This $\mathrm{Zn}$ mediated anionic polymerization in water could also be extended to other acryl acid derivatives, such as $\mathrm{N}, \mathrm{N}$-dimethylacrylamide (DMA, 74\% yield), acrylamide (AM, 84\% yield) and 2hydroxyethylmethylacrylate (HEMA, $92 \%$ yield). One of the main drawbacks of this $\mathrm{Li}_{2} \mathrm{Zn}(t-\mathrm{Bu})_{4}$-mediated polymerization in aqueous media is the impossibility of induce the polymerization of styrene (one of the most important synthetic polymers). In this 
case, deprotonation of the solvent took place before polymerization. ${ }^{[92]}$

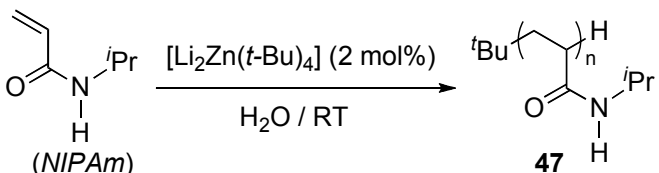

Scheme 22. $\mathrm{Li}_{2} \mathrm{Zn}(t-\mathrm{Bu})_{4}$ catalysed anionic polymerization of $\mathrm{N}$ isopropylacrylamide (NIPAm) in water.

Recently, Higashihara and co-workers reported another possibility for application of zincate $\mathrm{Li}_{2} \mathrm{Zn}(t-\mathrm{Bu})_{4}$ in polymerization reactions, that is through an exchange-cross-coupling process. ${ }^{[93]}$ Thus, when 2-bromo-3-hexyl-5-iodothiophene 48 was treated with $\mathrm{Li}_{2} \mathrm{Zn}(t-\mathrm{Bu})_{4}$, the iodine-zinc exchange reaction took place selectively. Upon heating to $60^{\circ} \mathrm{C}$ the resultant zincate 49 with the nickel catalyst $\left[\mathrm{Ni}(\mathrm{dppe}) \mathrm{Cl}_{2}\right]$ (dppe $=1,2-$ Bis(diphenylphosphino)ethane), polymerization proceeded in a controlled manner affording poly(3- $n$-hexylthiophene) $\mathbf{5 0}$ in high yield $(80-85 \%)$ and low polydispersions (PDls < 1.2). As analogously observed in the anionic polymerization of $\mathrm{N}$ isopropylacrylamide (NIPAm) in water, ${ }^{[91]}$ the high-molecularweight-polymer $\mathbf{5 0}$ could be obtained in a THF solution containing a small amount of water (Scheme 23).

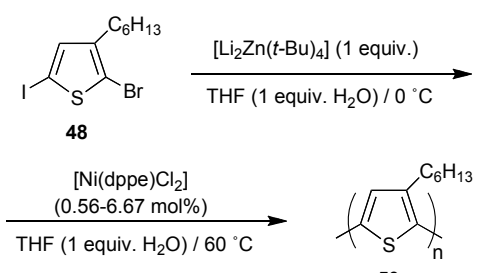

50

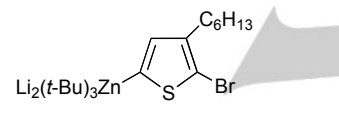

$$
49
$$<smiles>CC(=O)[C@H](N)Cc1ccc(I)cc1</smiles>

$\mathrm{R}-\mathrm{AuPPh}_{3}$

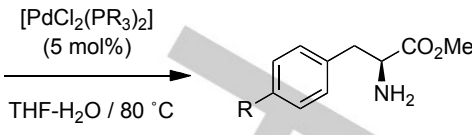

$\mathrm{R}=\mathrm{Ph}(62 \%) ; \mathrm{PhC} \equiv \mathrm{C}(60 \%)$

Scheme 24. Synthesis of 4-substituted phenylalanines in a mixture THFwater.

\subsection{Iridium-promoted $\mathrm{C}-\mathrm{H}$ bond activation in water}

Encapsulation of a variety of organometallic complexes into the internal cavity of hydrophilic supramolecular structures constitutes an innovative way to solubilise organometallic derivatives in aqueous media. ${ }^{[95]}$ In this context, Raymond and co-workers have incorporated the cationic iridium complexes $\left[\left(\mathrm{Cp}^{*}\right)\left(\mathrm{PMe}_{3}\right) \operatorname{lr}(\mathrm{Me})\left(\eta^{2}\right.\right.$-olefin][OTf] $\left(\eta^{2}\right.$-olefin = ethylene or cis-2butene) into a supramolecular $\left[\mathrm{Ga}_{4} \mathrm{~L}_{6}\right]$ tetrahedral assembly $(\mathrm{L}=$ 1,5-bis(2,3-dihydroxybenzoylamino)naphthalene) (Scheme 25). These species formed the host-guest complexes $\mathbf{5 1}$ and $\mathbf{5 2}$, stabilised by hydrophobic effects as well as by $\pi-\pi$ interactions between the coordinated olefin and the $\pi$-basic naphthalene walls of the host. ${ }^{[96]}$ The resulting water soluble host-guest systems $(\mathbf{5 1}, \mathbf{5 2})$ were then tested in the $\mathrm{C}-\mathrm{H}$ activation of aldehydes in aqueous media. In order to generate the active iridium species, decoordination of the olefin was preliminary required. The simple heating of the host-guests complexes (45 ${ }^{\circ} \mathrm{C}$ for 51 and $75^{\circ} \mathrm{C}$ for 52 ) facilitated olefin dissociation, thereby allowing the $\mathrm{C}-\mathrm{H}$ bond activation of the desired aldehyde. Interestingly, evidence for both size and shape selectivity was observed. Small aldehydes (e.g., acetaldehyde) are readily activated, whereas large aldehydes (e.g., benzaldehyde) are too large to fit inside the cavity. Also, the shape of the aldehyde proved to influence the reactivity of the encapsulated host-guest complex. For example, the host-guest complex reacted with isobutyraldehyde with a lower diastereoselectivity than with butyraldehyde. This experimental evidence was attributed to the more spherical shape of the isobutyraldehyde complex when compared to the butyraldehyde one.

\section{coupling reactions in aqueous media}

As previously discussed in Section 3.4, Pd-catalysed cross-coupling reactions are usually run with polarised organometallic nucleophiles (e.g., organoboron, organotin, organozinc, organomagnesium) in VOCs solvents. However, Sarandeses and co-workers have recently expanded the scope of this transformation first employing organogold(I)-phosphane derivatives $\left(\mathrm{RAuPPh}_{3}\right)$ as organometallic nucleophiles in water. Under these conditions, reactions between isolated aryl-, alkenyl-, or alkynylgold(I)-phosphanes and aryl halides or triflates were shown to proceed at room temperature (or at 80 ${ }^{\circ} \mathrm{C}$ ) in water/THF mixtures. ${ }^{[94]}$ These $\mathrm{Pd}$-catalysed reactions delivered the corresponding coupling products in good yield and with high chemoselectivity being compatible with free amino or hydroxyl groups present in the electrophile. As a proof of concept, this methodology was then successfully applied also to the preparation of substituted phenylalanine esters under protic conditions (Scheme 24).
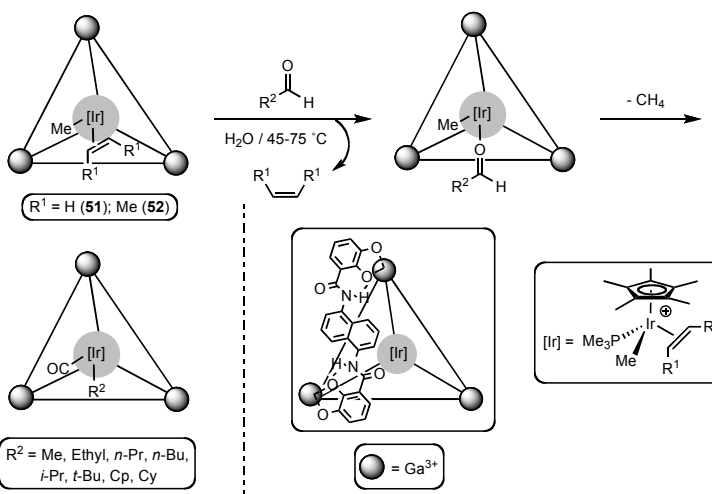

Scheme 25. C-H activation of aldehydes in aqueous media promoted by the water-soluble host-guest complexes 51,52. 


\section{Organometallic compounds of p-block elements}

Amongst the vast family of organometallic compounds, and within the subgroup of the p-block metals (elements whose valence electrons are in the $p$ orbital), organoaluminium ${ }^{[97]}$ and organotin ${ }^{[98]}$ members play a pivotal role in organic synthesis, finding widespread applications in a myriad of $\mathrm{C}-\mathrm{C}$ bond-forming processes. Although most of these reactivity studies have been performed using conventional VOCs, the potential of using these commodity organometallic reagents also in unconventional media (including ILs, DESs, $s c \mathrm{CO}_{2}$, and recently also neat water) has already been hinted at by several intriguing studies that will be discussed in this Section. In addition to these two important families of $p$-block metal reagents, the chemistry and applications of organoindium compounds are receiving increasing attention from the synthetic community, and are thus being rapidly developed. Bearers of an exceptional functional group tolerance and distinctive mild reactivity profiles, these compounds can render unique chemoselectivities in several C$\mathrm{C}$ bond forming reactions which are difficult to achieve using more polar reagents such as organolithium or organomagnesium reagents. Intriguingly and contrasting with the typical extreme moisture sensitivity of these polar organometallics, organoindium reagents can be utilised in aqueous media which allows the functionalisation of watersoluble substrates such as carbohydrates, as well as the development of greener synthetic methodologies. This unique behaviour was first reported by Li and Chan in 1991 through a seminal study assessing the allylation reactions of aldehydes and ketones under Barbier conditions in water, ${ }^{[99]}$ and nowadays it constitutes a signature attraction of organoindium chemistry. Of note, the chemistry of these reagents and their applications for the functionalisation of organic molecules (some of them employing aqueous media) have been recently summarised in a comprehensive review by Loh and co-workers. ${ }^{[100]}$ Thus, they will be not covered in this overview.

\subsection{Applications of Group 13 organometallic reagents}

Organoaluminium reagents have received considerable attention in recent years not only due to their high chemoselective reactivity and exceptional functional group tolerance, but also because of their relative cheapness, ready availability and comparative low toxicity. The polarity of their $\mathrm{Al}-\mathrm{C}$ bonds makes these commodity reagents extremely air and moisture sensitive, and they usually have to be manipulated under strict inertatmosphere techniques. Therefore, although at present most of their applications require the use of dry organic solvents, some promising studies have already glimpsed the potential of applying these compounds in ILS as an alternative reaction media. In 2006, Taddei and co-workers have reported the multistep synthesis of isoxazolines using the $I L$ [BMIM] $\left[\mathrm{BF}_{4}\right]$, where one of the key synthetic steps involves the transformation of an ester into an amide via an aluminium amide. This species is generated in situ by adding a solution of $\mathrm{AlMe}_{3}$ in toluene to a solution of the ester $\mathbf{5 3}$ and benzylamine furnishing $\mathbf{5 4}$ in $\mathbf{7 9 \%}$ yield (Scheme 26). ${ }^{[101]}$

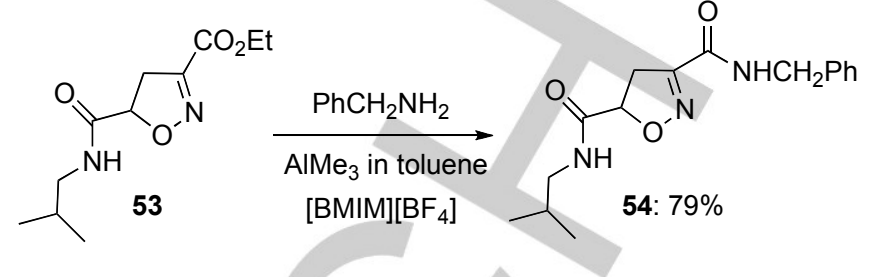

Scheme 26. Ester amidination of isoxazoline 53 with $\mathrm{AlMe}_{3}$ in the $I L$ $[\mathrm{BMIM}]\left[\mathrm{BF}_{4}\right]$

More recently, Chen and Liu have shown that aluminium alkyl and aryloxy compounds, used widely in polymerization processes, can effectively catalyse the conversion of glucose to HMF (5-hydroxymethylfurfural) using the IL 1-ethyl-3methylimidazolium chloride, [EMIM]Cl 55. ${ }^{[102]}$ Trying to shed some light on the constitution of the active Al species involved in this transformation, alkylaryloxy aluminium $\mathrm{MeAl}(\mathrm{OAr})_{2} 56(\mathrm{OAr}$ $=\mathbf{2}, 6$-di-tert-butyl-4-methylphenoxide) was mixed with $\mathbf{5 5}$, under the same glucose conversion conditions, and this enabled the isolation and subsequent structural elucidation of the new mixed imidazolium aluminate $\{\mathrm{ENIM}\}^{+}\left\{\mathrm{Me}(\mathrm{Cl}) \mathrm{Al}(\mathrm{OAr})_{2}\right\}^{-} \mathbf{5 7}$, where the chloride is now attached to $\mathrm{Al}$ (Scheme 27).

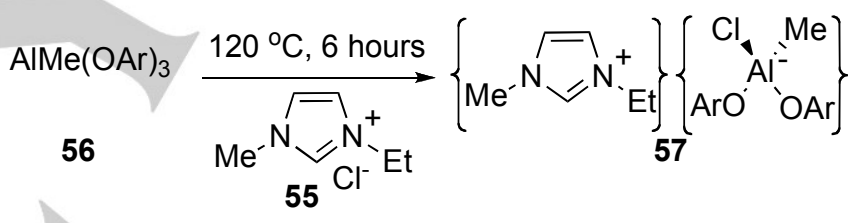

Scheme 27. Formation of imidazolium aluminate 57 by combining aluminium complex $\mathbf{5 6}$ with IL $\mathbf{5 5}$.

As already alluded to, indium can mediate Barbier-type reactions in water. ${ }^{[99,100]}$ Interestingly, metallic gallium can also be used to promote the allylation of aldehydes and ketones with allyl bromide in water, affording the relevant homoallyl alcohols in high yields. ${ }^{[103]}$ Similarly, the coupling of indoles and pyrroles with allyl halides can be accomplished in a mixture of water and DMF in the presence of $\mathrm{Ga}$ metal using $\mathrm{NBu}_{4} \mathrm{Br}$ as an additive. ${ }^{[104]}$ This method in granting access to C3-allylated indole species 58 represents a main-group metal-mediated alternative to other approaches employing $\mathrm{Pd}$ catalysts. Interestingly, the choice of solvent is crucial for the success of this transformation as a mixture of products results on using acetonitrile or THF. The effect of $\mathrm{NBu}_{4} \mathrm{Br}$ is also remarkable; in fact, the employment of other metal bromides such as $\mathrm{MgBr}_{2}$ or $\mathrm{KBr}$ inhibits the coupling process (Scheme 28). 


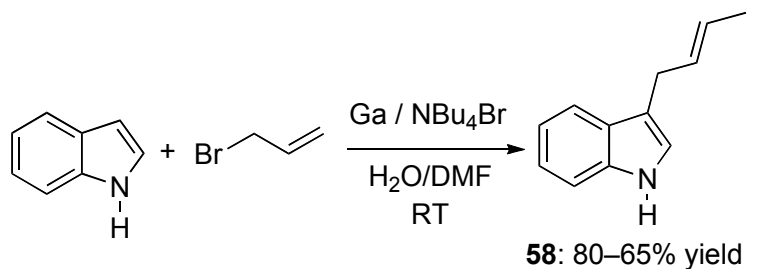

Scheme 28. Gallium-mediated allylation of indoles using a $\mathrm{H}_{2} \mathrm{O} / D M F$ mixture.

Oshima has shown that allylgallium reagents, generated in situ via salt metathesis of $\mathrm{GaCl}_{3}$ and allymagnesium bromide, promote radical allylation of $\alpha$-iodo and $\alpha$-bromo carbonyl compounds in the presence of $\mathrm{BEt}_{3}$ and under air, using a mixture of THF/hexane and water (Scheme 29). ${ }^{[105]}$ Interestingly, when assessing solvent effects, it was found that without using water as a co-solvent the yields in the formation of $\mathbf{5 9}$ were lowered significantly. Although the exact nature of this favourable solvent effect is unclear, the authors suggest the possible involvement of allylgallium hydroxide intermediates, which may be more reactive towards the radical allylation process.

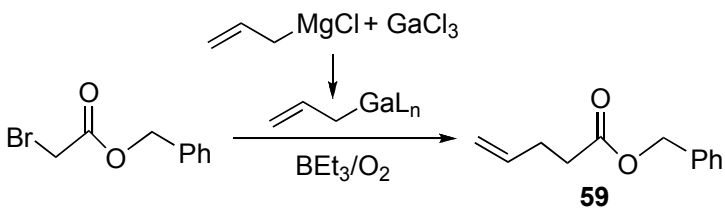

THF/hexane: 52\%; THF/hexane/ $\mathrm{H}_{2} \mathrm{O}: 78 \%$

Scheme 29. Triethylborane-induced radical allylation of a-halo carbonyl compounds with allylgallium reagent in aqueous media.

Significantly, indium-mediated allylation reactions cannot only be accomplished using water as the solvent. ${ }^{[100]}$ Alternative reaction media such as $I L s^{[106]}$ and $s c \mathrm{CO}_{2}{ }^{[107]}$ can be employed too. Indeed, Gordon and Ritchey have reported the use of indium metal and allyl bromide for the allylation of a wide range of aldehydes and ketones using $I L[B M I M]\left[B_{4}\right]$. These reactions can be carried out at room temperature using stoichiometric amounts of In to afford the relevant homoallylic alcohols in yields ranging from 37 to $92 \%$, which, in general, are comparable to those reported using organic solvents or water. ${ }^{[106 a]}$ Interestingly, this study reveals that, at the end of the reaction, addition of water to quench the putative indium alkoxide intermediate is essential in order to achieve the above yields for the relevant homoallylic alcohols. Using this approach for the allylation of 2 methoxycyclohexanone $(\mathbf{6 0})$, the level of diastereoselectivity towards the syn product $\mathbf{6 1}$ was greater $(\mathbf{6 1}: \mathbf{6 2}$ ratio $=18.6: 1)$ than using pure water or a THF-water mixture (Scheme 30 ).

Related to these studies is the work of Chan and coworkers who compared the ability of $\mathrm{In}, \mathrm{Sn}$ or $\mathrm{Zn}$ to mediate the

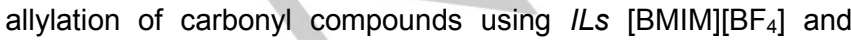
[EMIM] $\left[\mathrm{BF}_{4}\right]$. This study reveals that under ambient temperature conditions each metal can effectively promote the formation of the relevant homoallylic alcohols in the above solvent systems, although the best conversions are observed for Sn. ${ }^{[106 b]}$

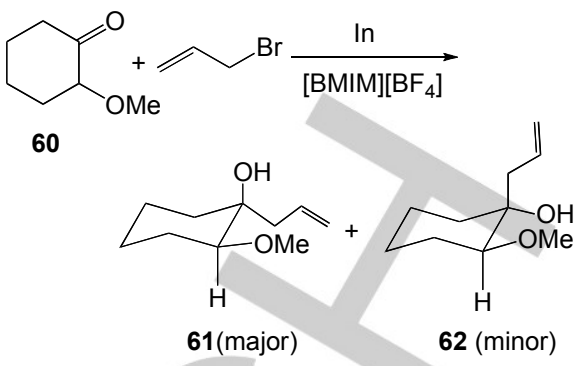

Scheme 30. Indium-mediated allylation of 2-methoxycyclohexanone 60 using $I L[B M I M]\left[B_{4}\right]$.

The same group has also shown that aldimines can undergo nucleophilic addition with allylindium reagents, generated in situ from In and allylbromide in a mixture of $I L s$ [bpy][BF 4$] /[\mathrm{bpy}][\mathrm{Br}]$ (bpy $=N$-butylpyridine), affording homoallylic amines 63 in good yields (66-99\%) (Scheme 31). Mechanistic studies have revealed that in these reaction media allylindium $(\mathrm{I})$ and allylindium(III) dibromide are in equilibrium, with the former being the most reactive towards imines in the formation of $\mathbf{6 3}$, whereas the latter accounts for the formation of the bis(allylated) amine 64. Interestingly, the use of bromide ion as an additive (in the form of $I L[b p y][B r])$ shifts the position of this equilibrium towards an $\ln (\mathrm{I})$ species, which promotes the selective formation of 63. ${ }^{[106 c]}$

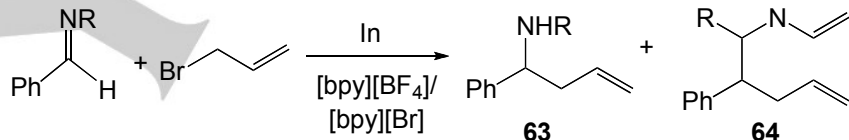

Scheme 31. Indium-mediated allylation of imines in $[\mathrm{bpy}][\mathrm{BF} 4] /[\mathrm{bpy}][\mathrm{Br}]$

From a more cost-effective perspective, Hirashita has reported the efficient allylation of carbonyl compounds in ILS using catalytic amounts of In, which can be generated in situ by reduction of $\mathrm{InCl}_{3}(10 \mathrm{~mol} \%)$ with stoichiometric aluminium. Notably, these reactions occur faster when water is added to the $I L[B M I M]\left[P_{6}\right]$, although it should be noted that when the same approach was employed using neat water as the solvent, the allylation process was completely shutdown. ${ }^{[106 d]}$ In addition, once In-mediated aldehyde allylation processes are carried out using liquid $\mathrm{CO}_{2}$ as the solvent, the relevant homoallylic alcohols can be isolated in 38 to $82 \%$ yield. ${ }^{[107]}$ This method represents a cleaner and efficient alternative to conventional organic solvents, where the excess of $\mathrm{CO}_{2}$ can be separated by depressurisation and subsequently be reused.

\subsection{Applications of organotin reagents}

Finding widespread applications in cornerstone synthetic methods (Stille coupling, radical reactions, allylations, etc.) organotin compounds are a family of versatile organometallic reagents. Part of their popularity stems from their thermal stability and relatively straightforward preparations combined with their robustness to hydrolysis and oxidation. Furthermore, these reagents are also compatible with a myriad of organic 
functional groups, showing an excellent balance between stability and reactivity. However, despite such an impressive synthetic background, one of their main drawbacks is related to their toxicity and the difficulties associated with the removal of residues from the final products. Some of the strategies developed to try to overcome this limitation include the use of organotin reagents supported by $I L s .{ }^{[108]}$ These reagents can be easily prepared by treating imidazole derivative 65 with Mel or EtBr forming the $I L$ supported tin reagent 66 that, in turn, can be used in Stille cross-coupling reactions, under solvent-free conditions and without the addition of additives or ligands, thereby affording a range of bis(aryl) compounds of the kind of 67 in good yields (Scheme 32).

$$
\text { quant. }
$$

Scheme 32. Synthesis of $I L 66$ and its application in a Stille cross-coupling reaction to give the biaryl derivative $67 .{ }^{[108 f]}$

Furthermore, it is possible to recycle the tin compound/catalyst system at the end of the reaction by extracting the organic products with an organic solvent. By treating the $I L$ phase containing the halogenotin-supported ionic liquid 68 with $\mathrm{PhLi}$, it is possible to generate the arylating starting material 66 (Figure 5). These organotin reagents can also be used as effective catalysts for the reductive amination of aldehydes and ketones using $\mathrm{PhSiH}_{3}$. Reactions can also be carried out under solventfree conditions, which facilitate the purification of the final products and minimise problems caused by tin contamination. ${ }^{[108 c]}$

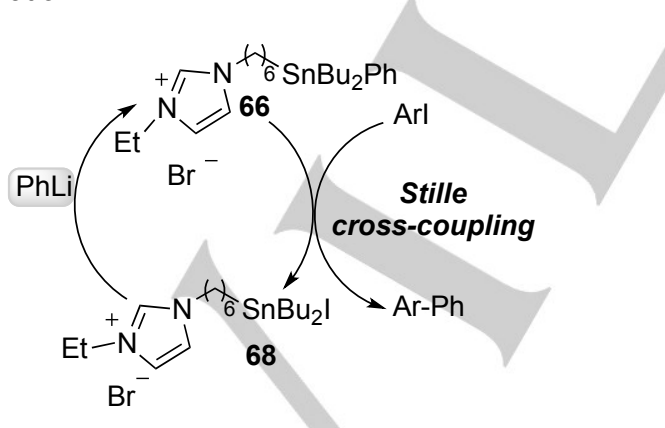

Figure 5. Recycling of $I L$-supported tin reagents 66.

It should also be noted that allylation reactions and Stille couplings, two of the most powerful synthetic applications of organotin reagents, have also been investigated using $I L s$ as alternative reaction media to organic solvents. Under these conditions, successful allylation methods of aldehydes and ketones have been reported using several tin reagents, including $\mathrm{Sn}$ metal, $\mathrm{SnCl}_{2}$ or tetra(allyl)tin. These reactions offer an excellent substrate scope and can be carried out at room temperature. Even more importantly, in many cases, the $I L$ can be efficiently recycled without any further purification, thus making these protocols more environmentally benign. ${ }^{[109]}$ Moreover, using tetra(allyl)tin it is possible to activate all-four allyl groups towards their transfer to the carbonyl substrates, thereby maximizing the atom-economy of the process. ${ }^{[109 a]}$ Related to this work is that by Kobayashi and co-workers who described a silica-gel-supported scandium system with an IL acting as a heterogeneous catalyst to efficiently promote several $\mathrm{C}-\mathrm{C}$ bond-forming processes, including the allylation of ketones using tetra(allyl)tin (Scheme 33). ${ }^{[10]}$ Intriguingly, this study shows that the key to success of this novel approach is the combination of a silica-gel-supported metal catalysts with an $I L$, which creates a hydrophobic reaction environment in water.

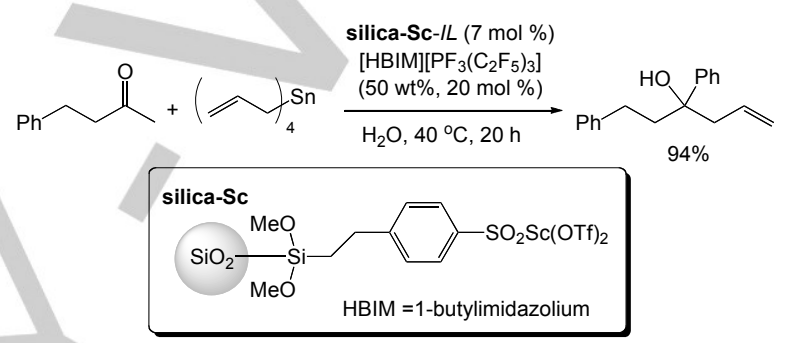

Scheme 33 Organotin-mediated allylation reaction catalysed by silica-Sc-IL in water.

Stille couplings of organostannanes catalysed by Pd complexes have also been studied in ILs. ${ }^{[111]}$ Pioneering work by Handy and Zhang, ${ }^{[112]}$ indeed, showed that Stille coupling reactions can be

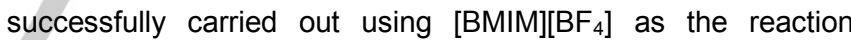
medium, thus allowing the effective recycling of the solvent and the catalyst without significant activity loss. Notably, these processes are particularly sensitive to the structure of the IL employed. ${ }^{[113]}$ For example, as illustrated in Scheme 34, once nucleophilic ILs such as [BMIM][Br] are used for the coupling of iodobenzene and tributylvinyl stannane under $\mathrm{Pd}(\mathrm{OAc})_{2}$ catalysis, compound 69 is isolated in very low yields. Conversely, the employment of $I L s$ with $\mathrm{N}$-containing anions such as $\left[\mathrm{NTf}_{2}\right]^{-}$ $\left(\mathrm{NTf}_{2}=\right.$ bis(trifluoromethylsulfonyl)imide) allowed higher conversions (up to 94\%) under ligand-free reaction conditions (Scheme 34). This dramatic difference in the $I L$ performance has been attributed by Chiappe and co-workers to the nucleophilic assistance of the anion $\mathrm{NTf}_{2}{ }^{-}$in the transmetallation step of the coupling reaction, which allows the coordination expansion of tin. ${ }^{[114]}$ On the contrary, a similar type of activation would be less likely to occur in [BMIM][Br], due to the stronger cation-anion interactions present in this $I L$. Notably, and despite the higher reactivity observed in these $\mathrm{NTf}_{2}$-based $I L s$, the stability of the catalyst is very low, which precludes the effective recycling of the system. 


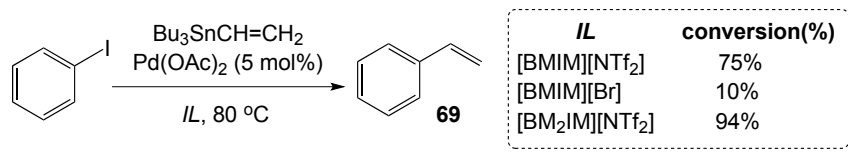

Scheme 34. Ligand-free Stille cross-coupling of iodobenzene with tributylvinyl stannane in ILs.

This drawback can be overcome by using Pd nanoparticles as catalysts rather than molecular palladium species. ${ }^{[115]}$ The versatility and tuneability of ILs allows the stabilisation of nanoparticles, protecting them from agglomeration, while increasing the robustness to oxidation and hydrolysis of the nanoscale catalyst surface thanks to the formation of a protective shell. In these reactions, $\mathrm{Pd}$ nanoparticles act as catalyst reservoirs, while the active catalytic species are molecular Pd complexes, which can be leached out from the surface of the nanoparticle. ${ }^{[116]} \mathrm{A}$ wide range of ILs have been assessed for this type of Stille coupling, containing a variety of cations (e.g., pyridinium, imidazolium, tetraalkyl ammonium). Notably, Dyson has shown that the use of nitrile functionalised ILs improved significantly the stability of the catalytic systems allowing their efficient recycling and minimising catalyst leaching. ${ }^{[15 b]}$ Employing Pd nanoparticles stabilised by tetraalkyl ammonium salts bearing long alkyl chains as catalyst, Nacci and co-workers have reported efficient Suzuki and Stille crosscouplings involving a wide range of halide aryls, including aryl chlorides, whose applications in these type of processes can be particularly challenging due to their reduced reactivity. ${ }^{[115 c]}$

$D E S s$ have also been successfully employed in Stille alkylations and biaryl synthesis. Köning and co-workers have reported that using low-melting mixtures of sugar, urea and inorganic salts as solvents it is possible to promote the fast and efficient Pd-catalysed alkyl transfer of tetraalkyltin reagents (Scheme 35). ${ }^{[117]}$ Using conventional organic solvents, the transfer of simple alkyl groups requires instead special conditions including the use of toxic solvents such as HMPA or DMF. The smooth formation of coupling products 70 (Scheme 35) using this alternative method has been attributed to the high polarity and nucleophilic character of the DES combinations employed. Biaryls $\mathbf{7 1}$ can also be prepared in almost quantitative yields using this approach, which works well with both electronpoor and electron-rich aryl bromides (Scheme 35). Interestingly, the catalyst load can be reduced to $0.001 \mathrm{~mol} \%$ and the catalyst-solvent mixture can be recycled up to three times. An added advantage to this approach is the simple work up and the ease at which products are isolated employing these melt mixtures; in fact, upon adding water, the organic products precipitate as amorphous solids and can be separated by filtration.

Although traditionally Stille couplings are carried out in organic solvents, the stability that aryl stannanes exhibit to air and moisture has allowed the development of alternative methods using water as the solvent. ${ }^{[118]}$ For example, Wolf has reported an effective Stille cross-coupling methodology using a wide range of aryl chlorides and aryl bromides. Using an airstable and water-soluble Pd-phosphinous acid catalyst, the synthesis of several bis(aryl) compounds can be accomplished in good to high yields, using neat water as the solvent and without the need of an organic co-solvent. ${ }^{[18 d]}$
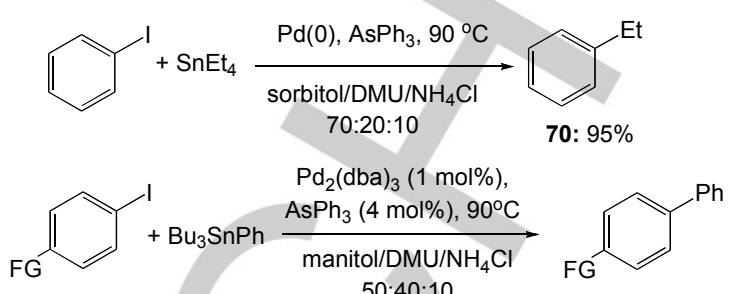

$\mathrm{FG}=\mathrm{OMe}: 100 \%$

$\mathrm{FG}=\mathrm{NO}_{2}: 95 \%$

Scheme 35. Stille couplings in sugar-urea-salt melts $(\mathrm{DMU}=$ dimethylurea $)$.

Interestingly, the catalyst can be recycled up to four runs with just a slight decrease in the observed yields (from $96 \%$ to $84 \%$ yield). Furthermore, these recycling studies demonstrate that under these conditions, the coupling products can be easily separated by extraction from the water-soluble catalyst. Notwithstanding, it should be noted that these reactions need to be carried out at high temperatures $\left(135-140^{\circ} \mathrm{C}\right)$ and over long periods of time (up to 24 hours). Milder reaction conditions for these couplings have been reported using dendrimer encapsulated $\mathrm{Pd}$ nanoparticles, which can catalyse Stille reactions in water at room temperature. ${ }^{[119]}$ However, the substrate scope of these approaches is relatively limited.

In this regard, Lipshutz and Lu have developed an alternative strategy which builds on their previous work on $\mathrm{Pd}$ catalysed Negishi cross-couplings in water (Scheme 20). ${ }^{[86]}$ The use of TPGS-750M as a surfactant (able to undergo selfassembly in water to form nanomicelles) and a $\mathrm{Pd}\left[\mathrm{P}(\mathrm{tBu})_{3}\right]_{2} / \mathrm{DABCO}$ (DABCO = 1,4-diazabicyclo[2.2.2]octane) combination as a catalyst, enables the efficient coupling of an impressive range of aryl and alkenyl halides to be conducted at room temperature with water as the only reaction medium. ${ }^{[120]}$ These reactions not only take place in high yields but, in some cases, they also offer greater and different stereoselectivities than when using conventional solvents, as shown in Scheme 36 for the formation of $\mathbf{7 2}$.

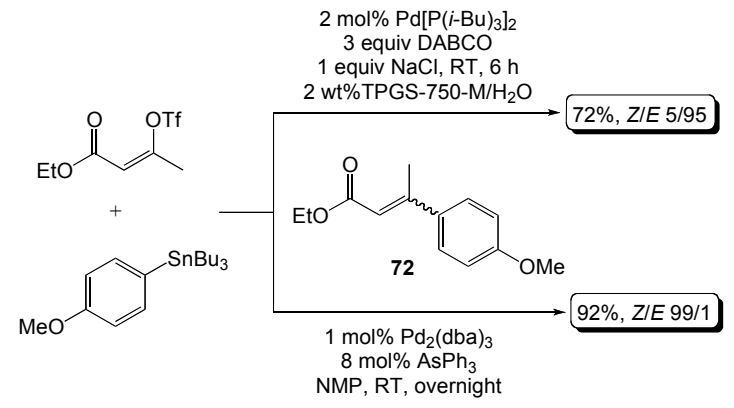

Scheme 36. Stille couplings with a Z-alkenyl triflate using NMP as the solvent and under aqueous micellar conditions. 
Using water as the solvent, a simple and efficient one-pot methodology has been developed by Duan and co-workers: with $\mathrm{Pd}\left(\mathrm{PPh}_{3}\right)_{4}$ as a catalyst, effective cross-coupling of a variety of aryl and heteroaryl bromides/iodides could be accomplished. ${ }^{[121]}$ This method requires the use of microwave irradiation and involves the sequential stannylation followed by a Stille crosscoupling process, as depicted in Scheme 37 for the synthesis of 73.

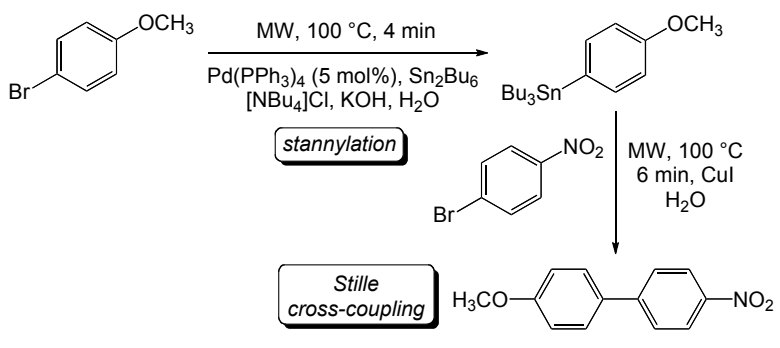

73: $92 \%$

Scheme 37. Open-pot stannylation/Stille cross-coupling sequential reactions.

\section{Conclusions}

Overall, it is clear from the examples discussed in this Microreview that the employment of unconventional reaction media in the chemistry of s-, p-, and d-block elements is taking the stage today transforming everything and everyone. In a world with dwindling petroleum resources, organometallic scientists are slowly but firmly nurturing their own ability to improve the environmentally friendliness of chemical processes so as to produce the best and original "green organometallic chemistry". The reticence to carry out the reactions of polar organometallic reagents under air, at room temperature, and in protic reaction media is also destined to fade away. The water itself, which is the most abundant and the only natural solvent on Earth, as well as the main traditional allied of biochemical processes, should no longer be considered a "foe" for organometallic compounds, but a "friend" to win.

The change in thinking will be the key to shift definitively our own paradigms and convictions. This will require a complete redesign of the experimental conditions, a deeper understanding of organometallic mechanisms and reactivities, and a close collaboration between theoreticians and experimental inorganic and organic researchers. In addition, fostering stronger industry/academic partnerships will expedite the transfer of new knowledge and emerging "greener technologies" to the marketplace to finally see realized in topic areas of science what they were simply considered not long ago as "fragile and visionary ideas". Now that the first seeds are being planted, it would be expected and desirable that this infant field would grow up and develop quickly beyond our present concepts, and that the lion's share of organometallic transformations (stoichiometric catalytic, and asymmetric applications) be designed and carried out mainly according to the "Green Chemistry" regulations. Until today, we have developed an extraordinary ability to adapt the word to our expectations. It is time now to adapt our expectations to fit the environment needs, hoping this may also lead to new scientific findings and to the disclosure of novel and unpredictable aspects of organometallic reactivity in the years to come!

Joaquín García Álvarez studied chemistry at the University of Oviedo and received his PhD degree in 2005 under the supervision of Prof. José Gimeno and Dr. Victorio Cadierno studying the coordination of iminophosphorane-phosphine and bis(iminophosphorane)methane ligands in arene-Ru(II) fragments. Then, he joined the group of Prof. Robert E. Mulvey at the University of Strathclyde in Glasgow (Scotland, United Kingdom) working for two years and a half in the field of main group chemistry (alkali-metal-mediated-metallation). He returned to the University of Oviedo in 2008 where he is currently a "Ramón y Cajal" postdoctoral researcher. The current focus of his research are: (i) the study of synthetic organic reactions mediated by highly-polarized organometallic compounds in green and bioreneweable reaction media (e.g., Deep Eutectic Solvents, $D E S s$ ), and (ii) the application of transition metal complexes (e.g., Ru, Re, $\mathrm{Pd}, \mathrm{Au}, \mathrm{Cu}, \mathrm{Ag}$ ) containing iminophosphorane ligands in homogeneous catalysis using environmentally friendly solvents (water, ionic liquids, glycerol and DESs) as reaction media. He is co-author of 45 publications and eight book chapters in the field of Organometallic Chemistry and Green Chemistry.

Eva Hevia received her MSci degree in Chemistry from the Universidad de Oviedo (Spain) in 1998. She obtained her PhD degree from the same institution in 2002 under the supervision of Victor Riera and Julio Pérez. Next she was awarded a Marie Curie Fellowship held at the University of Strathclyde under the direction of Prof. Robert Mulvey. In 2006 she took up a Royal Society University Research Fellowship at the University of Strathclyde where she is currently a Professor of Inorganic Chemistry. Her research interests include s-block metal-mediated transformations with a particular emphasis on metal-metal cooperativity and synergistic effects.

Vito Capriati obtained his MSci degree in Chemistry and Pharmaceutical Technology (summa cum laude) from the University of Bari "Aldo Moro" (Italy) in 1990. After working as a forensic chemist officer within the Carabinieri's RIS (Scientific Investigation Department) of Rome and earning a two-year graduate fellowship within the Italian National Research Council (CNR Centre MISO, then merged into ICCOM-CNR), in 1993 he became Assistant Professor before taking up his present appointment as Associate Professor of Organic Chemistry in the University of Bari in 2002, where he leads the Bioorganic and Organometallic group. He has been Visiting Scientist at The Ohio State University (USA) (Prof. Fraenkel's group) (2001), and Visiting Professor at the Göthenburg University (Sweden) (2003). He is co-founder of the academic spin-off SYNCHIMIA srl and departmenta coordinator of three Erasmus Programmes. His current research interests revolve around: functionalised organolithiums (structure elucidation, dynamic stereochemistry of chiral compounds, and the discovery of new reactions), synthesis and reactivity of new heterocycles, novel sustainable chemical processes using unconventional reaction media, organofluorine and organoboron chemistry, and the development of new drugs for rare diseases. He has published over 90 peer-reviewed journal articles, 5 book chapters and 7 reviews. He was the recipient of the CINMPIS Prize for 
"Innovation in Organic Synthesis" (2009), of the Award of the Italian Chemical Society (Organic Division) for "Mechanistic and Theoretical Aspects of Organic Chemistry" (2014), and the Italian coordinator of an international Italian-German bilateral Vigoni Project (2012-2013). Co-Editor of "Lithium Compounds in Organic Synthesis - From Fundamentals to Applications"; Publisher: Wiley-VCH (2014).

\section{Acknowledgements}

This research was supported by the Italian Ministero dell'Università e della Ricerca (MIUR) for financing the PON01_00862 Project, the Ateneo Italo-Tedesco (VIGONI programme 2012-2013, code E65E06000080001), and the Interuniversities Consortium CINMPIS. J.G.-A. is indebted to the MINECO of Spain (Projects CTQ2010-14796/BQU and CTQ2013-40591-P), the Gobierno del Principado de Asturias (Project GRUPIN14-006) and the COST action SIPs-CM1302 for financial support. J.G.-A. also thanks the MINECO and the European Social Fund for the award of a "Ramón y Cajal" contract. E.H. thanks the European Research Council (ERC) for generously supporting this work.

Keywords: organometallic compounds $\cdot$ water $\cdot$ deep eutectic solvents $•$ ionic liquids $\cdot$ reactivity

[1] R. Peoples, Foreword in Green Techniques for Organic Synthesis and Medicinal Chemistry (Eds.: W. Zhang, B. W. Cue, Jr.), Wiley-VCH Weinheim, Germany, 2012

[2] T. Laird, Org. Process Res. Dev. 2012, 16, 1-2.

[3] a) K. Shanab, C. Neudorfer, E, Shirmer, H. Spreitzer, Curr. Org. Chem. 2013, 17, 1179-1187; b) B. H. Lipshutz, S. Ghorai, Green Chem. 2014 16, 3660-3679; c) C. P. Ashcroft, P. J. Dunn, J. D. Hayler, A. S. Wells, Org. Process Res. Dev. 2015 DOI: 10.1021/op500276u; d) P. J. Dunn, A. S. Wells, M. T. Williams, Future Trends for Green Chemistry in the Pharmaceutical Industry in Green Chemistry in the Pharmaceutical Industry (Eds.: P. J. Dunn, A. S. Wells, M. T. Williams), Wiley-VCH Weinheim, Germany, 2010, pp. 333-355.

[4] D. J. Adams, P. J. Dyson, S. J. Tavener, Chemistry in Alternative Reaction Media, Wiley-VCH, Chichester, 2004

[5] a) Tetrahedron Organic Chemistry Series, Vol 23 Organolithiums: Selectivity for Synthesis (Ed.: J. Clayden), Pergamon, Amsterdam, 2002; b) The Chemistry of Organolithium Compounds (Eds.: Z. Rappoport, I. Marek), Wiley-VCH, 2004; c) Lithium Compounds in Organic Synthesis - From Fundamentals to Applications (Eds.: R. Luisi, V. Capriati), Wiley-VCH, 2014; d) V. Capriati, F. M. Perna, A. Salomone Dalton Trans. 2014, 43, 14204-14210; e) V. Capriati, S. Florio, R. Luisi, Eur. J. Org. Chem. 2014, 5397-5417; f) M. A. Perry, S. D. Rychnovsky, Nat. Prod. Rep. 2015, 32, 517-533; g) Grignard Reagents: New Development, (Ed.: H. G. Richey, Jr.), Wiley-VCH, New York 2000; h) R. W. Hoffmann, Chem. Soc. Rev. 2003, 32, 225-230; i) The Chemistry of Organomagnesium Compounds, (Eds.: Z. Rappoport, I. Marek), Patai Series, Wiley, Chichester, UK, 2008.

[6] The physicochemical properties (thermal stability, pyrophoricity, reactivity, etc.) of commercial organolithiums were proven to be dependent from the nature of hydrocarbon solution, the concentration, the presence of additives, and overall reflect the aggregates present in solution; see: T. L. Rathman, J. A. Schwindeman, Org. Process Res. Dev. 2014, 18, 1192-1210.
[7] R. Taylor, Tetrahedron Lett. 1975, 7, 435-436.

[8] a) N. S. Narasimham, R. Ammanamanchi, J. Chem. Soc., Chem. Comm. 1985, 1368-1369; b) P. Beak, C.-W. Chen, Tetrahedron Lett. 1985, 26, 4979-4980.

[9] R. Levine, M. J. Karten, W. M. Kadunce, J. Org. Chem. 1975, 40, 1770-1773.

[10] K. Smith, Annu. Rep. Prog. Chem., Sect. B 1975, 72, 136-149.

[11] For an excellent survey on this topic, see: T. L. Rathman, W. F. Bailey, Org. Process Res. Dev. 2009, 13, 144-151.

[12] S.-C. Kuo, F. Chen, D. Hou, A. Kim-Meade, C. Bernard, J. Liu, S. Levy, G. G. Wu, J. Org. Chem. 2003, 68, 4984-6987.

[13] P. Wipf, S. Lim. Angew. Chem. 1991, 105, 1095-1097; Angew. Chem. Int. Ed. Engl. 1993, 32, 1068-1071.

[14] H. W. Roesky, M. G. Walawalkar, R. Murugavel, Acc. Chem. Res. 2001, 34, 201-211.

[15] H. W. Roesky, R. Murugavel, M. G. Walawalkar, Chem. Eur. J. 2004 10, 324-331.

[16] R. Murugavel, S. Kuppuswamy, Chem. Eur. J. 2008, 14, 3869-3873.

[17] B. J. Wakefield, Organolithium Methods, Academic Press, London, 1988.

[18] Y. Pocker, J. H. Exner, J. Am. Chem. Soc. 1968, 90, 6764-6773.

[19] D. Barr, P. R. Raithby, P. von R. Schleyer, R. Snaith, D. S. Wright, J. Chem. Soc., Chem. Comm. 1990, 643-645.

[20] P. Mikulcik, P. R. Raithby, R. Snaith, D. S. Wright, Angew. Chem. 1991 103, 452-454; Angew. Chem. Int. Ed. Engl. 1991, 4, 428-430.

[21] C. Lambert, P. von R. Schleyer, U. Pieper, D. Stalke, Angew. Chem. 1992, 104, 78-79; Angew. Chem. Int. Ed. Engl. 1992, 31, 77-79.

[22] L. W. Chung, T. H. Chan, Y.-D. Wu, Organometallics 2005, 24, 1598 1607.

[23] G. Osztrovszky, T. Holm, R. Madsen, Org. Biomol. Chem. 2010, 8, 3402-3404

[24] J. Tammiku-Taul, P. Burk, A. Tuulmets, J. Phys. Chem. A 2004, 108, 133-139.

[25] V. Mallardo, R. Rizzi, F. C. Sassone, R. Mansueto, F. M. Perna, A Salomone, V. Capriati, Chem. Comm. 2014, 50, 8655-8658.

[26] A. P. Abbott, G. Capper, D. L. Davies, R. K. Rasheed and V. Tambyrajah, Chem. Commun. 2003, 70-71.

[27] For recent reviews, see: a) Caroline Ruß, B. König, Green Chem. 2012, 14, 2969-2982; b) Q. Zhang, K. De Oliveira Vigier, S. Royer, F. Jérôme, Chem. Soc. Rev. 2012, 41, 7108-7146; c) Y. Gu, F. Jérôme, Chem. Soc. Rev. 2013, 42, 9550-9570; d) M. Francisco, A. van den Bruinhorst, M. C. Kroon, Angew. Chem. 2013, 125, 3152-3163; Angew. Chem. Int. Ed. 2013, 52, 3074-3085; e) E. Smith, A. P. Abbott, K. S. Ryder, Chem. Rev. 2014, 114, 11060-11082; f) J. García-Álvarez, Deep Eutectic Solvents and Their Applications as New Green and Biorenewable Reaction Media, in Handbook of Solvents, vol. 2, $2^{\text {nd }}$ Edn: Use, Health, and Environment (Ed.: G.Wypych), ChemTec Publishing, Toronto, 2014

[28] F. C. Sassone, F. M. Perna, A. Salomone, S. Florio, V. Capriati, Chem Comm. 2015, 51, 9459-9462.

[29] C. Vidal, J. García-Álvarez, A. Hernán-Gómez, A. R. Kennedy, E. Hevia Angew. Chem., 2014, 126, 6079-6083; Angew. Chem. Int. Ed. 2014 53, 5969-5973.

[30] H. Zong, H. Huang, J. Liu, G. Bian, L. Song, J. Org. Chem. 2012, 77 4645-4652.

[31] M. J. Earle, K. R. Seddon, Pure Appl. Chem. 2000, 72, 1391-1398.

[32] a) P. Wassercheid, T. Welton, Ionic Liquids in Synthesis, Wiley-VCH, Weinheim, 2008; b) J. P. Hallet, T. Welton, Chem. Rev. 2011, 111 3508-3576.

[33] T. Ramnial, D. D. Ino, J. A. C. Clyburne, Chem. Comm. 2005, 325-327.

[34] T. Ramnial, S. A. Taylor, M. L. Bender, B. Gorodetsky, P. T. K. Lee, D. A. Dickie, B. M. McCollum, C. C. Pye, C. J. Walsby, J. A. C. Clyburne, J. Org. Chem. 2008, 73, 801-812.

[35] T. Itoh, K. Kude, S. Hayase, M. Kawatsura, Tetrahedron Lett. 2007, 48, 7774-7777. 
[36] T. Ramnial, S. A. Taylor, J. A. C. Clyburne, C. J. Walsby, Chem. Comm. 2007, 2066-2068.

[37] V. Jurcik, R. Wilhem, Green Chem. 2005, 7, 844-848.

[38] S. T. Handy, J. Org. Chem. 2006, 71, 4659-4662.

[39] M. C. Law, K.-Y. Wong, T. H. Chan, Chem. Comm. 2006, 2457-2459.

[40] L. Ford, F. Atefi, R. D. Singer, P. J. Scammels, Eur. J. Org. Chem. 2011, 942-950.

[41] A. Kadam, M. Nguyen, M. Kopach, P. Richardson, F. Gallou, Z.-K. Wan, W. Zhang, Green Chem. 2013, 15, 1880-1888.

[42] a) P. R. Jenkins in Organometallic Reagents in Synthesis, Oxford University Press, Oxford, 1994; b) I. Omae in Applications of Organometallic Compounds, Wiley, Chichester, 1998; c) B. M. Trost in Formation of Carbon-Carbon Bond via Organometallic Reagents, from Modern Organic Synthesis (Eds.: G. Zweifel, M. Nantz), W. H. Freeman, New York, 2007 and reference cited therein.

[43] a) P. Knochel, R. D. Singer, Chem. Rev. 1993, 93, 2117-2188; b) E. Erdik in Organozinc Reagents in Organic Synthesis, CRC Press, Boca Raton, 1996; c) P. Knochel, H. Leuser, L.-Z. Gong, S. Perrone, F. F. Kneisel in Functionalized Organozinc Compounds, from The Chemistry of Organozinc Reagents: R-Zn (Eds.: Z. Rappoport, I. Marek), John Wiley and Sons, Hoboken, 2006, pp 287-394; d) F. Chemla, F. Ferreira, O. Jackowski, L. Micouin, A. Perez-Luna in Carbon-Carbon Bond Forming Reactions Mediated by Organozinc Reagents, from Metal-Catalyzed Cross-Coupling Reactions and More (Eds.: A. de Meijere, S. Bräse, M. Oestreich), Wiley-VCH Verlag $\mathrm{GmbH} \&$ Co. KGaA, Weinheim, 2014, pp 276-364.

[44] a) E. Erdik, Tetrahedron 1984, 40, 641-657; b) B. H. Lipshutz, S. Sengupta, Org. React. 1992, 41, 135-631; c) B. Breit, Y. Schmidt, Chem. Rev. 2008, 108, 2928-2951; d) N. Krause in Modern Organocopper Compounds (Ed.: N. Krause), Wiley-VCH, Weinheim, 2005; e) P. Knochel, X. Yang, N. Gommerman in Handbook of Functionalized Organometallics. Applications in Synthesis Vol. 2 (Ed. P. Knochel), Wiley-VCH, Weinheim, 2005, pp 379-398.

[45] a) P. T. Anastas, J. C. Warner in Green Chemistry Theory and Practice, Oxford University Press, Oxford, 1998; b) A. S. Matlack in Introduction to Green Chemistry, Marcel Dekker, New York, 2001; c) M. Poliakoff, J. M. Fitzpatrick, T. R. Farren, P. T. Anastas, Science 2002, 297, 807810; d) M. Lancaster in Green Chemistry: An Introductory Text, RSC Publishing, Cambridge, 2002.

[46] P. T. Anastas in Handbook of Green Chemistry, Vol. 4, 5 and 6, Green Solvents: Volume 4: Supercritical Solvents (Eds.: W. Leitner, P. G. Jessop); Volume 5: Reactions in Water (Ed.: C.-J. Li); Volume 6: Ionic Liquids (Eds.: P. Wasserschied, A. Stark), Wiley- $\mathrm{VCH}$, Weinheim, 2010.

[47] E. Frankland, Q, J. Chem. Soc. 1850, 2, 263-296.

[48] a) S. Reformatsky, Ber. Dtsch. Chem. Ges. 1887, 20, 1210-1211; b) S. Reformatsky, J. Russ. Phys. Chem. Soc. 1890, 22, 44-64.

[49] For a review covering the Reformatsky reaction in conventional dry organic solvents, see: R. Ocampo, W. R. Dolbier Jr., Tetrahedron 2004 60, 9325-9374.

[50] For selective reviews dealing with Reformatsky-type reactions in the presence of water, see: a) C.-J. Li, Chem. Rev. 1993, 93, 2023-2035 b) C.-J. Li, Tetrahedron 1996, 52, 5643-5668; c) C.-J. Li, Chem. Rev. 2005, 105, 3095-3165

[51] a) T. H. Chan, C.-J. Li, Z. Y. Wei, J. Chem. Soc., Chem. Commun. 1990, 505-507; b) T. H. Chan, C.-J. Li, Z. Y. Wei, Can. J. Chem. 1994 $72,1181-1197$.

[52] W. L. Bieber, I. Malvestiti, E. C. Storch, J. Org. Chem. 1997, 62, 90619064.

[53] T. Kitazume, K. Kasai, Green Chem. 2001, 3, 30-32.

[54] P. Barbier, Compt. Rend. 1899, 128, 110-111.

[55] a) M. S. Kharasch, O. Reinmuth in Grignard reactions of nonmetallic substances, Prentice-Hall, 1954; b) J. C. Stowell in Carbanion in Organic Synthesis, Wiley, 1979; c) E. Negishi in Organometallics in Organic Synthesis Vol. 1, Wiley, 1980; d) B. J. Wakefield in
Comprehensive Organometallic Chemistry Vol. 7, Chapter 44, Pergamon, 1982.

[56] a) T.-H. Chan, M. B Isaac, Pure Appl. Chem. 1996, 68, 919-924; b) S Kobayashi in Aqueous Phase Organometallic Catalysis, Wiley- $\mathrm{VCH}$ Weinheim, 1998; c) L. Leseurre, J.-P. Genet, V. Michelet in Handbook of Green Chemistry (Eds.: P. T. Anastas, C.-J. Li), Wiley-VCH Weinheim, 2010; d) Metal-Catalyzed Reactions in Water (Eds.: P. H. Dixneuf, V. Cadierno), Wiley-VCH, 2013. See also ref. 50.

[57] B. Movassagh, M. Navidi, Tetrahedron Lett. 2008, 49, 6712-6714.

[58] C.-J. Li, T. H. Chan, Organometallics 1991, 10, 2548-2549.

[59] a) M. Lombardo, S. Morganti, C. Trombini, J. Org. Chem. 2003, 68 , 997-1006; b) M. Lombardo, S. Morganti, F. d'Ambrosio, C. Trombini, Tetrahedron Lett. 2003, 44, 2823-2826; c) K. Surendra, N. S. Krishnaveni, K. R. Rao, Tetrahedron Lett. 2006, 47, 2133-2136; e) Z. Zha, Z. Xie, C. Zhou, M. Chang, Z. Wang, New J. Chem. 2003, 27, 1297-1300; f) M. S. Reddy, M. Narender, Y. V. D. Nageswar, K. R. Rao, Synth. Commun. 2007, 37, 1983-1988; g) Y. Z. Gao, X. Wang, L. D. Sun, L. G. Xie, X. H. Xu, Org. Biomol. Chem. 2012, 10, 3991-3998.

[60] a) S. M. Cenci, L. R. Cox, G. A. Leeke, ACS Sustainable Chem. Eng 2014, 2, 1280-1288.

[61] Addition of dialkylzinc to aldehydes in different supercritical fluids $\left[s c \mathrm{CHF}_{3}\right.$ and supercritical ethane $\left.\left(s c \mathrm{C}_{2} \mathrm{H}_{6}\right)\right]$ has been previously reported: P. G. Jessop, R. A. Brown, M. Yamakawa, J. Xia, T. Ikariya M. Kitamura, S. C. Tucker, R. Noyori, J. Supercrit. Fluids 2002, 24 161-172.

[62] a) L. W. Bieber, M. F. da Silva, R. C. da Costa, L. O. S. Silva Tetrahedron Lett. 1998, 39, 3655-3658; b) S. Arimitsu, J. M. Jacobsen, G. B. Hammond, Tetrahedron Lett. 2007, 48, 1625-1628.

[63] L. W. Bieber, E. C. Storch, I. Malvestiti, M. F. da Silva, Tetrahedron Lett 1998, 39, 9393-9396.

[64] C. C. K. Keh, C. Wei, C.-J. Li, J. Am. Chem. Soc. 2003, 125, 4062 4063.

[65] F. Zhou, C.-J. Li, Nat. Chem., 2014, 5, 4254-4260

[66] T. Basile, A. Bocoum, D. Savoia, A. Umani-Ronchi, J. Org. Chem. 1994, 59, 7766-7773.

[67] a) H. Miyabe, M. Ueda, T. Naito, Chem. Commun. 2000, 2059-2060; b) M. Ueda, H. Miyabe, O. Miyata, T. Naito, Tetrahedron 2009, 65, 13211326.

[68] Y.-S. Yang, Z.-L. Shen, T.-P. Loh, Org. Lett. 2009, 11, 1209-1212.

[69] See, for example: a) P. Perlmutter in Conjugate Addition Reactions in Organic Synthesis, Pergamon, Oxford, 1992; b) B. E. Rossiter, N. M. Swingle, Chem. Rev. 1992, 92, 771-806; c) B. H. Lipshutz in Organometallics in Synthesis: A Manual (Ed.: M. Schlosser), John Wiley \& Sons, New York, 1994, pp. 283-382; d) M. P. Sibi, S. Manyen, Tetrahedron 2000, 56, 8033-8061; e) N. Krause, A. Hoffmann-Röder Synthesis 2001, 171-196; f) J. Christoffers, G. Koripelly, A. Rosiak, M. Rössle, Synthesis 2007, 1279-1300; g) C. Hawner, A. Alexakis, Chem Commun. 2010, 46, 7295-7306.

[70] A. Alexakis, J. Frutos, P. Mangeney, Tetrahedron: Asymmetry 1993, 4, 2427-2430

[71] For a feature article covering the positive effects obtained by addition of catalytic or stoichiometric quantities of water to either organic or organometallic processes, see: S. Ribe, P. Wipf, Chem. Commun. 2001, 299-307.

[72] G. Delapierre, T. Constantieux, J. M. Brunel, G. Buono, Eur. J. Org Chem. 2000, 2507-2511.

[73] It has also been reported that addition of water to Me $\mathrm{Zn}$ produces a stronger Lewis acid capable of activating benzaldehyde towards dimethylzinc addition. It is worth noting that this reaction does not take place in the absence of water; see ref. 71

[74] E. J. Corey, F. J. Hannon, N. W. Boaz, Tetrahedron 1989, 45, 545-555.

[75] B. H. Lipshutz, S. Huang, W. W. Y. Leong, G. Zhong, N. A. Isley, J. Am. Chem. Soc. 2012, 134, 19985-19988.

[76] a) C. Pitrier, C. Dupuy, J.-L. Luche, Tetrahedron Lett. 1986, 27, 3149 3242; b) L. Luche, C. Allavena, Tetrahedron Lett. 1988, 29, 5369-5372 
c) C. Dupuy, C. Petrier, L. A. Sarandeses, J.-L. Luche, Synth. Commun. 1991, 21, 643-651.

[77] F. F. Fleming, S. Gudipati, Org. Lett. 2006, 8, 1557-1559.

[78] a) J. L. Mascareñas, J. Perez-Sestelo, L. Castedo, A. Mouriño, Tetrahedron Lett. 1991, 32, 2813-2816; b) J. Perez Sestelo, J. L. Mascareñas, L. Castedo, A. Mourino, J. Org. Chem. 1993, 58, 118 123; c) J. Perez-Sestelo, J. L. Mascareñas, L. Castedo, A. Mouriño, Tetrahedron Lett. 1994, 35, 275-278; d) R. M. Suarez, J. Perez Sestelo, L. A. Sarandeses, Synlett 2002, 1435-1438; e) J. Perez Sestelo, I. Cornella, O. de Uña, A. Mouriño, L. A. Sarandeses, Chem. Eur. J. 2002, 8, 2747-2752; f) J. Perez Sestelo, O. de Uña, A. Mouriño, L. A. Sarandeses, Synlett 2002, 719-722; g) I. Cornella, J. Perez Sestelo, A. Mouriño, L. A. Sarandeses, J. Org. Chem. 2002, 67, 47074714; h) R. M. Suarez, J. Perez Sestelo, L. A. Sarandeses, Chem. Eur. J. 2003, 9, 4179-4187; i) R. M. Suarez, J. Perez Sestelo, L. A Sarandeses, Org. Biomol. Chem. 2004, 2, 3584-3587; j) I. Cornella, R. M. Suarez, A. Mouriño, J. Perez Sestelo, L. A. Sarandeses, J. Steroid Biochem. Mol. Biol. 2004, 89-90.

[79] a) P. Blanchard, M. S. El Kortbi, J.-L. Fourrey, M. Robert-Gero, Tetrahedron Lett. 1992, 33, 3319-3322; b) E. J. Maria, A. D. Da Silva J.-L. Fourrey, Eur. J. Org. Chem. 2000, 627-631.

[80] a) S. Raussou, N. Urbain, P. Mangeney, A. Alexakis, N. Platzer, Tetrahedron Lett. 1996, 37, 1599-1602; b) P. Mangeney, L. Hamon, S Raussou, N. Urbain, A. Alexakis, Tetrahedron 1998, 54, 10349-10362.

[81] Similar intramolecular addition to different electron-deficient olefins has also been reported; see: D. Sakuma, H. Togo, Tetrahedron 2005, 61 10138-10145

[82] See, for example: a) N. Miyaura in Cross-coupling Reactions: a Practical Guide, Springer, Berlin, 2002; b) A. de Meijere, F. Diederich in Metal-catalyzed Cross-coupling Reactions, $2^{\text {nd }}$ Edition, Wiley- $\mathrm{VCH}$ Weinheim, 2004; c) Y. Nishihara in Applied Cross-coupling Reactions Springer, Berlin, 2013.

[83] a) E. Negishi, L. F. Valente, M. Kobayashi, J. Am. Chem. Soc. 1980 102, 3298-3299; b) M. Kobayashi, E. Negishi, J. Org. Chem. 1980, 45 5223-5225; c) E. Negishi, Acc. Chem. Res. 1982, 15, 340-348; d) E. Negishi, S. Gagneur in Handbook of Organopalladium Chemistry for Organic Synthesis, Vol. 1, (Ed.: E. Negishi), Wiley, New York, 2002

[84] a) A. Krasovskiy, C. Duplais, B. H. Lipshutz, J. Am. Chem. Soc. 2009, 131, 15592-15593; b) A. Krasovskiy, C. Duplais, B. H. Lipshutz, Org Lett. 2010, 12, 4742-4744; c) C. Duplais, A. Krasovskiy, A Wattenberg, B. H. Lipshutz, Chem. Commun. 2010, 46, 562-564; d) V Krasovskaya, A. Krasovskiy, B. H. Lipshutz, Chem. Asian J. 2011, 6 1974-1976; e) V. Krasovskaya, A. Krasovskiy, A. Bhattacharjya, B. H. Lipshutz, Chem. Commun. 2011, 47, 5717-5719; f) A. Krasovskiy, I. Thomé, J. Graff, V. Krasovskaya, P. Konopelski, C. Duplais, B. H. Lipshutz, Tetrahedron Lett. 2011, 52, 2203-2205; g) C. Duplais, A Krasovskiy, B. H. Lipshutz, Organometallics 2011, 30, 6090-6097; h) B. H. Lipshutz, S. Ghorai, A. R. Abela, R. Moser, T. Nishikata, C. Duplais, A. Krasovskiy, R. D. Gaston, R. C. Gadwood, J. Org. Chem. 2011, 76, 4379-4391; i) P. Klumphu, B. H. Lipshutz, J. Org. Chem. 2014, 79, 888-900.

[85] Jackson and co-workers have employed the Lipshutz "in water" conditions to protect iodoaniline with iodobenzene; see: A. J. Ross, F Dreiocker, M. Scäfer, J. Oomens, A. J. H. M. Meijer, B. T. Pickup, R. F. W. Jackson, J. Org. Chem. 2011, 76, 1727-1734.

[86] N. A. Isley, M. S. Hageman, B. H. Lipshutz, Green Chem. 2015, 17 893-897.

[87] S. M. Kelly, B. H. Lipshutz, Org. Lett. 2014, 16, 98-101.

[88] a) J. Sirieix, M. Oßberger, B. Betzemeier, P. Knochel, Synlett 2000, 1613-1615; b) B. Betzemeier, P. Knochel, Angew. Chem. Int. Ed. Engl. 1997, 36, 2623-2624.

[89] a) M. Uchiyama, M. Koike, M. Kameda, Y. Kondo, T. Sakamoto, J. Am. Chem. Soc. 1996, 118, 8733-8734; b) M. Uchiyama, Y. Kondo, T. Miura, T. Sakamoto, J. Am. Chem. Soc. 1997, 119, 12372-12373; c) M. Uchiyama, M. Kameda, O. Mishima, N. Yokoyama, M. Koike, Y.
Kondo, T. Sakamoto, J. Am. Chem. Soc. 1998, 120, 4934-4946; d) S. Nakamura, M. Uchiyama, T. Ohwada, J. Am. Chem. Soc. 2004, 126 11146-11147; e) S. Nakamura, M. Uchiyama, T. Ohwada, J. Am. Chem. Soc. 2005, 127, 13116-13117; f) S. Nakamura, M. Uchiyama, J. Am. Chem. Soc. 2007, 129, 28-29.

[90] For related aspects of the unique reactivity of $\mathrm{Li}_{2} \mathrm{Zn}(t-\mathrm{Bu})_{4}$, see: a) $\mathrm{M}$. Kobayashi, Y. Matsumoto, M. Uchiyama, T. Ohwada, Macromolecules 2004, 37, 4339-4331; b) M. Uchiyama, T. Furuyama, M. Kobayashi, Y Matsumoto, K. Tanaka, J. Am. Chem. Soc. 2006, 128, 8404-8405.

[91] T. Furuyama, M. Yonehara, S. Arimoto, M. Kobayashi, Y. Matsumoto, M. Uchiyama, Chem. Eur. J. 2008, 14, 10348-10356.

[92] Organozinc catalysts were patented by E. J. Vandenberg for the polymerization of epoxides and episulfides in water. The exact nature of the zinc active species was not reported, but the authors assessed that some of the zinc-to-carbon bonds present in the primordial organozinc reagent should be retained in the polymerization catalyst; see: E. J. Vandenberg, U.S. Patent 1972, 3,639,267.

[93] T. Higashihara, E. Goto, M. Ueda, ACS Macro. Lett. 2012, 1, 167-170.

[94] M. Peña-López, L. A. Sarandeses, J. Perez-Sestelo Eur. J. Org. Chem. 2013, 2545-2554

[95] a) D. H. Leung, R. G. Bergman, K. N. Raymond, J. Am. Chem. Soc 2007, 129, 2746-2747; b) C. J. Brown, G. M. Miller, M. W. Johnson, R G. Bergman, K. N. Raymond, J. Am. Chem. Soc. 2011, 133, 11964 11966.

[96] M. D. Pluth, R. G. Bergman, K. N. Raymond, "Selective Stoichiometric and Catalytic Reactivity in the Confines of a Chiral Supramolecula Assembly" in Supramolecular Catalysis (Ed.: P. W. N. M van Leeuwen) Wiley-VCH, Germany, 2008, pp. 165-197.

[97] For reviews on the structure, preparation, and applications of organoaluminum reagents in organic synthesis, see: a) "Modern Organoaluminum Reagents: Preparation, Structure, Reactivity and Use", in Topics in Organometallic Chemistry, Vol. 41 (Eds.: S. Woodward, S. Dagorne), Springer, Berlin, 2013; b) K. Maruoka, H. Yamamoto, Tetrahedron 1988, 44, 5001-5032; c) C. Wang, Z.Xi, Chem. Soc. Rev. 2007, 36, 1395-1406; d) W. Uhl, Coord. Chem. Rev. 2008 252, 1540-1563.

[98] a) "Tin Chemistry. Fundamentals, Frontiers, and Applications" (Eds.: A. G. Davies, M. Gielen, K. H. Pannell, E. R. T. Tiekink), Wiley: Chichester, 2008; b) B. Carsten, F. He, H. J. Son, T. Xu, L. Yu, Chem. Rev. 2011 111, 1493-1528; c) M. M. Heravi, E.. Hashemi, F. Azimian, Tetrahedron 2014, 70, 7-21; d) C. Cordovilla, C. Bartolomé, J. M. Martinéz-llarduya, P. Espinet, ACS Catal. 2015, 5, 3040-3053.

[99] C. J. Li, T. H. Chan, Tetrahedron Lett. 1991, 32, 7017-7020.

[100] Z. L. Sheng, S. Y. Wang, Y. K. Chok, Y. H. Xu, T. P. Loh, Chem. Rev. 2013, 113, 271-401.

[101] M. Rodriguez, A. Sega, M. Taddei, Org. Lett. 2006, 5, 4029-4031.

[102] D. D. Liu, E. Y. X. Chen, Appl. Catal. A-Gen. 2012, 435, 78-85

[103] Z. Wang, S. Yuan, C. J. Li, Tetrahedron Lett. 2002, 43, 5097-5099.

[104] D. Prajapati, M. Gohain, B. J. Gogoi, Tetrahedron Lett. 2006, 47, 35353539

[105] S. Usugi, H. Yorimitsu, K. Oshima, Tetrahedron Lett. 2001, 42, 45354538

[106] a) C. M. Gordon, C. Ritchie, Green Chem. 2002, 4, 124-128; b) M. Chun, K.Y. Wong, T. H. Chan, Green Chem. 2002, 4, 161-164; c) M. C. Law, T. W. Cheung, K.-Y. Wong, T. H. Chan, J. Org. Chem. 2007, 72, 923-929; d) T. Hirashita, Y. Sato, D. Yamada, F. Takahashi, S. Araki Chem. Lett. 2011, 40, 506-507.

[107] J. X. Haberman, G. C. Irvin, V. T. John, C. J. Li, Green Chem. 1999, 1 , 265-267.

[108] a) P. D. Pham, J. Vitz, C. Chamignon, A. Martel, S. Legoupy, Eur. J. Org. Chem. 2009, 3249-3257; b) P. D. Pham, S. Legoupy, Tetrahedron Lett. 2009, 50, 3780-3782; c) P. D. Pham, P. Bertus, S. Legoupy, Chem. Commun. 2009, 6207-6209; d) J. Vitz, D. H. Mac, S. Legoupy, Green Chem. 2007, 9, 431-433; e) D. Faye, M. Vybornyi, F. Boeda, S Legoupy, Tetrahedron Lett. 2013, 69, 5421-5425; f) N. Louaisil, P. D. 
Pham, F. Boeda, D. Faye, A. S. Castanet, S. Legoupy, Eur. J. Org Chem. 2011, 143-149.

[109] For selected references, see: a) P. Galleti, F. Moretti, C. Samori, E. Tagliavini, ChemSusChem. 2009, 2, 1045-1050; b) A. McCluskey, J. Garner, D. J Young, S. Caballero, Tetrahedron Lett. 2000, 41, 81478151; c) L. Tang, L. Ding, W. X. Chang, J. Li, Tetrahedron Lett. 2006 47, 303-306; d) R. Slaton, A. Petrone, R. Manchanayakage Tetrahedron Lett. 2011, 52, 5073-5076.

[110] Y. Gu, C. Ogawa, J. Kobayashi, Y. Mori, S. Kobayashi, Angew. Chem. 2006, 118, 7375-7378; Angew. Chem. Int. Ed. 2006, 45, 7217-7220.

[111] M. Keßler, J. D. Scholten, F. Gralbrecht, M. H. Prechlt, in Palladium Catalyzed Coupling Reactions: Practical Aspects and Future Developments, (Ed.: A. Molnár), Wiley-VCH, Weinheim, Germany, 2013

[112] S. T. Handy, X. Zhang, Org. Lett. 2001, 3, 233-236.

[113] C. Chiappe, G. Imperato, E. Napolitano, D. Pieraccini, Green Chem. 2004, 6, 33-36.

[114] For a theoretical study on the influence on the coordination expansion of $\mathrm{Sn}$ and its implications in the trasmetallation step in Stille coupling processes, see: V. Farina, E. Napolitano, Organometallics 2003, 22 , 4030-4037.

[115] a) C. Chiappe, D. Pieraccini, D. Zhao, Z. Fei, P. J. Dyson, Adv. Synth. Catal. 2006, 348, 68-74; b) D. Zhao, Z. Fei, T. J. Geldbach, R. Scopelliti, P. J. Dyson, J. Am. Chem. Soc. 2004, 126, 15876-15882; c) V. Calò, A. Nacci, A. Monopoli, F. Montingelli, J. Org. Chem. 2005, 70, 6040-6044.

[116] See, for example: a) M. H. G. Prechtl, M. Scariot, J. D. Scholten, G Machado, S. R. Teixeira, J. Dupont, Inorg. Chem. 2008, 47, 89959001; b) M. H. G. Prechtl, P. S. Campbell, J. D. Scholten, G. B. Fraser, G Machado, C.C. Santini, J. Dupont, Y. Chauvin, Nanoscale. 2010, 2 2601-2606.

[117] G. Imperato, R. Vasold, B. Köning, Adv. Synth. Catal. 2006, 348, 2243 2247.

[118] For selected references, see: a) A. I. Roshchin, N. A. Bumagin, I. P. Beletskaya, Tetrahedron Lett. 1995, 36, 125-128; b) R. Rai, K. B. Aubrecht, D. B. Collum, Tetrahedron Lett. 1995, 36, 3111-3114; c) S.K. Kang, T.-G. Baik, S.-Y. Song, Synlett 1999, 3, 327-329; d) C. Wolf R. Lerebours, J. Org. Chem. 2003, 68, 7551-7554.

[119] a) J. C. Garcia-Martinez, R. Lezutekong, R. M. Crooks, J. Am. Chem. Soc., 2005, 127, 5097-5103; b) M. A. Bernechea, M. E. de Jesús, C López-Mardomingo, P. Terreros, Inorg. Chem., 2009, 48, 4491-4496.

[120] G. Lu, C. Cai, B. H. Lipshutz, Green Chem. 2013, 15, 105-109.

[121] X. Tan, Z. J. Zhou, J. X. Zhang, X. H. Duan, Eur. J. Org. Chem. 2014 5153-5157.
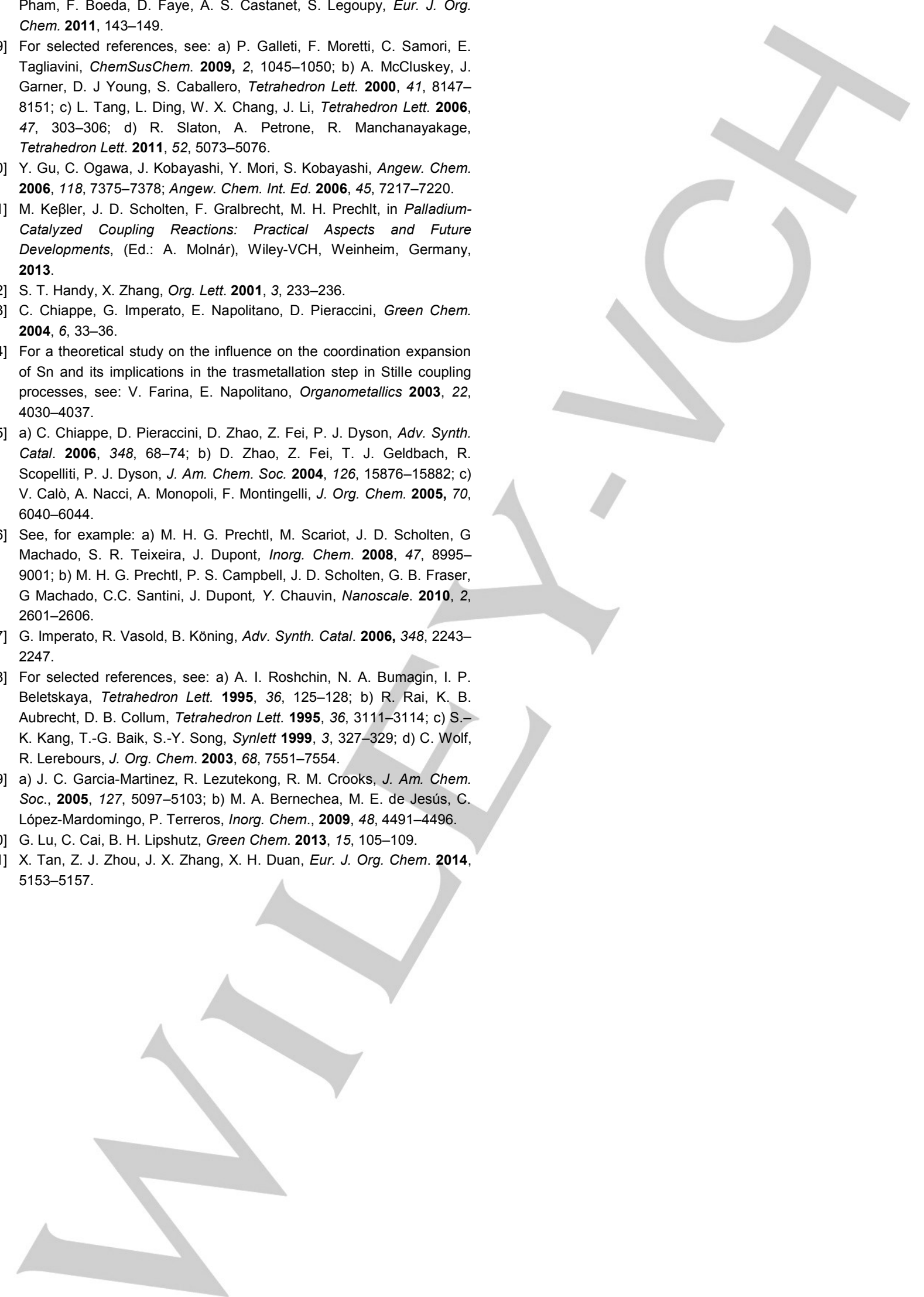


\section{MICROREVIEW}

Stepping towards ideal polar organometallic processes! This Microreview provides a reliable evidence of the unstoppable transition of polar organometallic chemistry towards greener protocols, mainly represented by unconventional solvents. This contributes to make organometallic chemistry even more sustainable and prepares the ground for new, stimulating research.

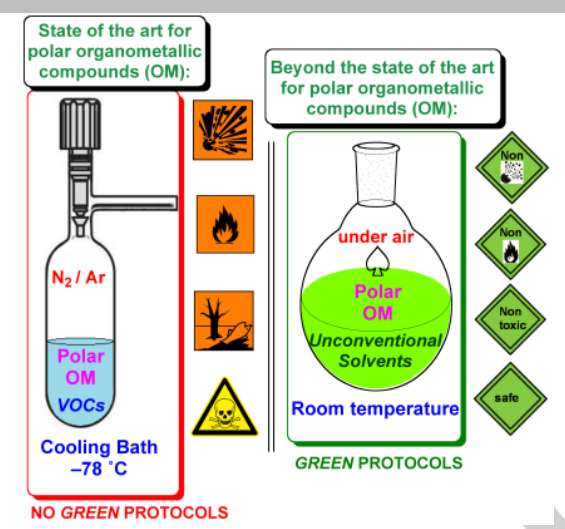

\section{Green Chemistry}

Joaquin García-Álvarez, *Eva Hevia, * and Vito Capriati*

Page No. - Page No.

Reactivity of Polar Organometallic Compounds in Unconventional Reaction Media: Challenges and Opportunities 